\title{
Migração intrametropolitana e mobilidade pendular: evidências para a região metropolitana do Recife
}

\author{
Hilton Martins de Brito Ramalho \\ Professor - Universidade Federal da Paraíba (UFPB) \\ Endereço: Rua Norberto de Castro Nogueira, 123 - Jardim Oceania - João Pessoa/PB \\ CEP: 58037-603 - E-mail: hilton@ccsa.ufpb.br
}

\section{Danyella Juliana Martins de Brito}

Doutoranda - Universidade Federal de Minas Gerais (UFMG-CEDEPLAR)

Endereço: Av. Antônio Carlos, 6627 - Belo Horizonte/MG

CEP: 31270-901 - E-mail: danybrito@cedeplar.ufmg.br

Recebido: 07/06/2014. Aceite 27/07/2016.

\section{Resumo}

O artigo investiga se há relação entre mobilidade pendular e migrações na Região Metropolitana do Recife (RMR). Nesse intuito, foram usados dados do Censo Demográfico de 2010 e estimado um modelo econométrico baseado em cópulas e que incorpora autosseleção de trabalhadores entre migrantes e não migrantes. Os resultados sugerem uma relação complementar entre as escolhas de cidade de residência e de cidade de trabalho no meio intrametropolitano; fato que reforça a hipótese de influência direta do processo de descentralização urbana sobre os movimentos pendulares. As estimativas mostraram que um trabalhador com histórico recente de migração na RMR tem, em média, 47,6 p.p. a mais de probabilidade de efetuar a mobilidade pendular quando comparado a um não migrante. Esse efeito tende a ser subestimado quando se ignora a autosseleção dos migrantes em habilidades inatas.

\section{Palavras-Chave}

Mobilidade pendular. Região Metropolitana do Recife. Seletividade das migrações.

\begin{abstract}
The aim of this paper is to investigate the relationship between commuting and labor migration in the Recife Metropolitan Area (RMR), Brazil. We use data from Demographic Census of 2010 to estimate a copula-based model of intrametropolitan commuting which takes accounting self-selection of migration. Our finds suggest that changing in residence and work places are complements in the metropolitan area. This evidence reinforces the role of the urban decentralization process in the commuting. In addition, the results showed that a migrant worker has on average 47.7 points more in probability of working in another city than a worker who have never moved from its city of birth. We also observe a downward bias in the estimates when we ignore the self-selection in migration.
\end{abstract}

\section{Keywords}

Commuting. Recife's Metropolitan Region. Self-selection in migration flows.

\section{JEL Classification}

R23. J24. C31. 


\section{Introdução}

A estrutura espacial de grandes aglomerados urbanos está associada à dinâmica populacional e à distribuição das atividades econômicas ao longo do tempo. Nessas áreas, a mobilidade espacial de trabalhadores e empresas tem sido relacionada a um conjunto de fatores que incluem acessibilidade, amenidades, custos e tempo relativos aos deslocamentos para o local de trabalho, lazer, mercado de habitação, meio ambiente, criminalidade e oferta de serviços públicos (MIRANDA; DOMINGUES, 2010). Destarte, quando há diferenças espaciais no tocante a esses fatores, indivíduos com objetivos comuns e de mesma classe social tendem a se aglomerar em determinadas áreas, favorecendo a dissociação entre cidade de moradia e de trabalho (ÂNTICO, 2005; MOURA; DELGADO; COSTA, 2013).

O crescimento do território metropolitano e de sua rede de infraestrutura urbana (integração local), a saber transportes, comunicações, comércio e serviços, também estimulam a mobilidade pendular (MOURA; BRANCO; FIRKOWSKI, 2005; JARDIM, 2011). ${ }^{1}$ Destarte, o estudo desse fenômeno ganha relevância para o desenho de políticas públicas, uma vez que o mesmo pode estar associado à demanda por serviços públicos, especialmente por infraestrutura rodoviária, qualidade de transportes coletivos e moradia.

A literatura especializada tem abordado a questão da mobilidade pendular a partir da investigação dos determinantes envolvidos nas escolhas individuais de residência e de local de trabalho. Em abordagens teóricas recentes (ZAX, 1994; FREEDMAN; KERN, 1997), a escolha de onde morar e onde trabalhar estão inter-relacionadas, pois afetam a jornada ao trabalho, e, por conseguinte, o bem-estar individual. Um indivíduo otimizador pode realocar sua posição residencial e de local de trabalho como resposta a alterações em amenidades locais (acesso ao lazer e cultura), disponibilidade de residências, oportunidades de emprego, estrutura domiciliar (quantidade de filhos, existência de cônjuge) e investimento em capital humano (educação e treinamento). Assim, mudanças de preços nos mercados de habitação, trabalho, transporte, consumo e educação podem gerar

1 Os movimentos pendulares são entendidos como deslocamentos cotidianos realizados do local de residência para o local de trabalho no contexto inter-regional (PAPANIKOLAOU, 2006; AXISA; SCOTT; NEWBOLD, 2012). No Brasil, a maioria dos estudos especializados costuma classificar como commuter a pessoa que trabalha em um município diferente daquele de residência (ARANHA, 2005; ÂNTICO, 2005; MOURA; DELGADO; COSTA, 2013). 
diferentes padrões em termos de migração intrametropolitana (realocação de residência) e de mobilidade pendular (alteração do local de trabalho), dependendo do benefício líquido esperado.

Apesar dos recentes esforços teóricos de associação entre as escolhas de realocação residencial (migração) e de local de trabalho (commuting), a maioria dos estudos empíricos documentados na literatura ainda costuma tratar os fenômenos de migração e de mobilidade pendular de forma desconexa (LUNDHOLM, 2010). Por outro lado, pesquisas recentes têm produzido evidências empíricas que associam diretamente a mobilidade residencial à mobilidade pendular, isto é, mostram indícios de que a migração e o commuting no meio urbano são movimentos complementares (RENKOW; HOOVER, 2000; AXISA; SCOTT; NEWBOLD, 2012). Os resultados desses estudos também favorecem à hipótese de descentralização urbana como fator influente sobre migrações e movimentos pendulares. Ou seja, processos de desconcentração de atividades econômicas e de mercados residenciais (crescimento de subúrbios) favorecem aglomerações com relação positiva entre taxa de imigrantes (novos residentes) e taxa de residentes que trabalham em outras localidades próximas (trabalhadores pendulares). Nesse contexto, a presença de muitos imigrantes nas chamadas cidades dormitórios (onde há muitos residentes trabalhando em localidades próximas) pode ser resultado de respostas individuais a alterações espaciais nos preços de habitação, transporte (acessibilidade) e oportunidades de trabalho.

Outra questão que permeia a discussão sobre escolha residencial e escolha de local de trabalho é a possível diferença de habilidades inatas entre migrantes e não migrantes. Estudos sobre migração do trabalho baseados na abordagem do capital humano fornecem evidências de que os migrantes são positivamente selecionados, isto é, trabalhadores não aleatórios na população que, em média, são mais instruídos, jovens, motivados, perseverantes, amantes do risco quando comparados às pessoas que nunca mudaram de residência (CHISWICK, 1999; DOS SANTOS JÚNIOR; MENEZES FILHO; FERREIRA, 2005). Nesse sentido, há evidências que indivíduos com histórico de migração tendem a auferir salário médio superior aos não migrantes, assim como, podem ser mais hábeis na aquisição de informações sobre postos de trabalho em diferentes localidades e no acesso a redes sociais (grupos de parentes, conhecidos, grupos religiosos, grupos de trabalhadores etc.). Em outras palavras, a presença 
de seletividade no grupo de migrantes reforça a conjectura de que esses indivíduos podem tomar decisões de mobilidade pendular distintas daquelas observadas para o grupo de não migrantes, especialmente quando se defrontam com mudanças de preços relacionados aos mercados de habitação, trabalho e custos de acesso à informação.

No Brasil, a mobilidade pendular tem sido abordada no contexto das principais áreas metropolitanas, com destaque para São Paulo, Rio de Janeiro e Belo Horizonte (ÂNTICO, 2005; MOURA; BRANCO; FIRKOWSKI, 2005; JARDIM; ERVATTI, 2007; MIRANDA; DOMINGUES, 2010; JARDIM, 2011; MOURA; DELGADO; COSTA, 2013). Nesses estudos, a despeito da ausência de rigor empírico, fatores como custos atrelados ao transporte e o tempo/ distância envolvidos nos trajetos casa-trabalho são destacados como importantes condicionantes dos movimentos pendulares intrametropolitanos. Por outro lado, parece haver uma importante lacuna na literatura nacional, uma vez que pouco se conhece a respeito da relação entre as dinâmicas migratória e pendular nas metrópoles brasileiras. Afinal, as decisões de mudança de residência na esfera metropolitana e de cidade de trabalho são escolhas complementares ou substitutas? Se a mobilidade pendular é maior no grupo de migrantes, os não migrantes deveriam ter maior prioridade ou subsídios no tocante a políticas públicas de acesso à moradia em áreas suburbanas? E quanto às políticas de mobilidade urbana, esse último grupo deveria ter transporte público subsidiado? Tais questões sugerem que a investigação da temática em destaque pode auxiliar no norteamento de políticas públicas em espaços urbanos.

Nesse contexto, ainda vale ressaltar que, desde os anos de 1970, o Brasil parece sofrer um processo de "inversão demográfica". O estudo de Soares (2006), por exemplo, caracteriza tal fenômeno como uma desconcentração populacional nas capitais em função do crescimento de outros municípios no entorno das regiões metropolitanas. Esse processo seria potencializado pela especulação imobiliária e por fatores ligados ao próprio mercado de trabalho, como a incapacidade de absorção de toda mão de obra disponível em razão do distanciamento dos núcleos urbanos. Ademais, os dados mais recentes do Censo Demográfico de 2010, realizado pelo Instituto Brasileiro de Geografia e Estatística (IBGE), mostram que, no país, 13,5\% das pessoas ocupadas que realizavam o trajeto diário casa-trabalho tinham emprego fora do município de residência. Entre as principais 
Regiões Metropolitanas brasileiras, a Região Metropolitana do Recife (RMR) chama a atenção por registrar a maior participação de trabalhadores pendulares entre a população ocupada (31\%), indicador bastante superior àqueles observados para as demais metrópoles do Nordeste, a saber $10,7 \%$ e $9,8 \%$ de taxa de mobilidade pendular, respectivamente, para Fortaleza e Salvador. ${ }^{2}$

Diante do exposto, este estudo investiga se há relação entre mobilidade pendular (escolha de local de trabalho) e migração intrametropolitana (escolha de residência), tendo como área de análise a RMR. Para tanto, foram utilizados dados do Censo Demográfico de 2010 e um modelo econométrico de efeito-tratamento endógeno, no qual se testa como a decisão de mobilidade pendular responde a um processo prévio de seleção não aleatória entre migrantes e não migrantes.

$\mathrm{O}$ artigo encontra-se dividido em sete seções incluindo essa introdução. Na segunda seção, apresenta-se uma revisão da literatura especializada. A terceira seção traz um breve panorama acerca da mobilidade pendular na RMR e sua associação com variáveis de acessibilidade, habitação e migração. A quarta seção é dedicada a estratégia empírica, em que se discute o modelo econométrico e técnica de estimação. Na quinta seção faz-se uma apresentação sobre os dados empregados e recortes amostrais. Os resultados empíricos são discutidos na sexta seção. Por fim, a sétima seção é reservada às considerações finais.

\section{Revisão de literatura}

Os movimentos pendulares estão relacionados ao processo de configuração espacial das atividades econômicas. De maneira análoga aos fluxos migratórios, os deslocamentos pendulares não podem ser dissociados das teorias da localização espacial, uma vez que a distribuição das atividades produtivas é resultado da interação de forças centrípetas (aglomerativas) e centrífugas (dispersão) responsáveis pelas economias e deseconomias de aglomeração (LÖSCH, 1954; VON THÜNEN, 1966). O crescimento das cidades e, por conseguinte, dos fatores interligados a esse processo podem ser restringi-

\footnotetext{
2 Os dados tabulados para as maiores metrópoles brasileiras podem ser consultados na Tabela
} A.1 do apêndice. 
dos, especialmente porque é possível que economias de aglomeração se transformem em deseconomias - tais como a associação positiva entre grau de urbanização e congestionamentos nos centros urbanos (GLAESER, 1998).

Muth (1969) construiu um modelo teórico que leva em consideração a influência da acessibilidade à área central de negócios sobre a localização dos domicílios, o consumo de serviços de habitação e a intensidade de uso da terra. Mills (1972), por sua vez, desenvolveu um modelo de equilíbrio urbano que demonstra como os custos de deslocamento pendular variam com a distância das áreas centrais de negócios. Nesse modelo, o deslocamento pendular é assumido como inteiramente determinado pela localização residencial, que, por sua vez, depende de custos de habitação e custos de deslocamento ao local de trabalho. Mills (1972) assinala que, em equilíbrio, a mobilidade pendular produz um montante de congestionamento, de tal forma que os custos de viagem e de habitação satisfaçam certa condição de equilíbrio locacional. Além disso, outro resultado do modelo é o considerável congestionamento e elevado custo dos deslocamentos pendulares perto do centro da cidade. A partir desses achados, o autor em destaque discute acerca da dificuldade, e ao mesmo tempo, da necessidade de melhoria da eficiência dos sistemas de transportes urbanos.

Brueckner (1987) apresentou uma abordagem unificada da versão de Muth-Mills do modelo urbano. Seu enfoque recai em torno da observação fundamental de que as diferenças de custos de pendularidade dentro de uma área urbana deve ser equilibrada por distintos preços de moradia. Assim, o referido autor primeiro discute as implicações do modelo, para, em seguida, fazer uma análise de estática comparativa do equilíbrio urbano. Neste sentido, nota-se que os consumidores que vivem longe da área central de negócios devem ser compensados de alguma forma por seus longos e onerosos deslocamentos pendulares, caso contrário, ninguém iria viver voluntariamente longe das áreas centrais. Essa compensação assume a forma de um preço relativamente inferior pela habitação nas localidades mais afastadas, em comparação aquelas mais próximas da área central de negócios. 
Evers e Van der Veen (1985) foram uns dos primeiros autores a estudar empiricamente os movimentos pendulares e sua relação com migrações. Tais autores fazem uma análise exploratória da mobilidade - diga-se migração e deslocamento pendular do trabalho - e desenvolvem um quadro explicativo das inter-relações entre estes dois fenômenos. No estudo, um modelo logit foi utilizado, com o propósito de incorporar variáveis de escolhas que envolvem local de trabalho e local de residência, tornando possível a definição de interações entre a migração e os movimentos pendulares, isto é, relações de complementaridade e/ou de substituição.

Nesse contexto, Renkow e Hoover (2000) analisaram as hipóteses de "reestruturação regional" e de "desconcentração da população", as quais implicam diferentes previsões para a relação entre deslocamento pendular e migração. Esses autores desenvolveram um teste empírico para essas duas conjecturas, baseado no modelo teórico de escolha residencial e de local de trabalho proposto por Zax (1994). A análise empírica foi conduzida para os condados que compõem o estado da Carolina do Norte, nos Estados Unidos. Os resultados econométricos corroboram a hipótese de desconcentração populacional, no sentido de que a força dominante subjacente às tendências da dinâmica da população rural-urbana tem sido, no período de análise (1970-1980 e 1980-1990), a urbanização relacionada a mudanças nas preferências residenciais. Ou seja, os referidos autores encontraram uma relação direta entre mobilidade pendular e taxas defasadas de migração.

Lundholm (2010) examinou as relações entre migração inter-regional e deslocamentos pendulares na Suécia durante os anos de 1970, 1985 e 2001. Através de regressões logísticas, em que a propensão a migrar foi examinada por um conjunto de variáveis independentes, tais como o tamanho do mercado de trabalho e características individuais dos migrantes, o autor em foco constatou que a propensão a migrar diminui com a idade, o casamento e a presença de crianças no domicílio. A maior densidade de trabalho no município parece reduzir a probabilidade de migração - evidenciando a importância do tamanho do mercado de trabalho. Também foi observado que os

3 A hipótese de reestruturação regional sustenta que mudanças na distribuição espacial das oportunidades de emprego são determinantes para a forte mudança na distribuição relativa do crescimento populacional urbano e rural. Por outro lado, a hipótese de desconcentração populacional atribui essas mudanças às alterações nas preferências residenciais de trabalhadores e consumidores (RENKOW; HOOVER, 2000). 
deslocamentos pendulares desempenham um papel de substituto à migração para aqueles indivíduos que vivem em localidades com maior disponibilidade de vagas de emprego, e, por outro lado, os indivíduos que vivem em áreas de menor disponibilidade de trabalho são induzidos a migrar, para aumentar suas chances de emprego.

Axisa, Scott e Newbold (2012) analisaram a relação entre o tempo de migração e a duração do deslocamento pendular na área metropolitana de Toronto (Canadá), ao questionar se as maiores distâncias pendulares são aquelas percorridas pelos migrantes recentes. Esses autores identificaram distâncias médias casa-trabalho maiores para indivíduos entre 30 e 44 anos de idade $(17,1 \mathrm{~km})$; as mulheres registraram distâncias mais curtas $(12,9 \mathrm{~km})$, em relação aos homens $(17,2 \mathrm{~km})$; e a distância do trabalho aumenta na medida em que a renda familiar se eleva, assim como quando os indivíduos possuem trabalhos mais qualificados. Através de estimativas utilizando o método de Mínimos Quadrados Ordinários (MQO), o estudo conclui que viver em áreas rurais mais acessíveis e ser migrante recente são características que estão diretamente associadas com trajetos mais longos casa-trabalho. Assim, descobrem que quanto maior o tempo que o indivíduo mora naquela localidade, menores distâncias casatrabalho serão percorridas por ele.

Os achados de Axisa, Scott e Newbold (2012) também corroboram outros estudos que relacionam as distâncias percorridas nos deslocamentos pendulares com a migração, ao sugerir que migrantes recentes têm, em média, trajetos pendulares maiores em relação aos indivíduos classificados como residentes de longa duração na mesma área (CHAMPION; COOMBES; BROWN, 2009; FINDLAY et al., 2001). Uma justificativa apontada para a ocorrência de tal fenômeno é a existência de um intervalo de adaptação no período logo após a migração. Assim, o deslocamento pendular poderia assumir um caráter temporário (AXISA; SCOTT; NEWBOLD, 2012).

Sandow e Westin (2010) investigaram a duração dos movimentos pendulares de longa distância na Suécia - os trajetos casa-trabalho com $30 \mathrm{~km}$ ou mais de distância $-{ }^{4}$, e quais os fatores que caracterizam os indivíduos que se deslocam por períodos mais curtos ou mais longos. Dado que a decisão por realizar o deslocamento pendular é

4 A distância de $30 \mathrm{~km}$ equivale a um tempo de deslocamento de 45 minutos, relatado como um limite para a propensão a aceitar os deslocamentos pendulares (SANDOW; WESTIN, 2010). 
algo que afeta a família e não apenas o indivíduo que o realiza, foram observados efeitos dos movimentos pendulares de longa distância para ambos os cônjuges de um domicílio, em termos de resultados econômicos. Para tanto, os autores em destaque utilizaram uma base de dados abrangente, que cobre os passageiros de longa distância na Suécia, em 2000, e seu comportamento pendular ao longo de um período de uma década (1995-2005). Através de análises de regressão multivariada e regressão logística multinomial, foi observado que a experiência anterior de ter realizado deslocamentos pendulares de longas distâncias torna os indivíduos mais propensos a ter uma longa duração desses movimentos. Outra descoberta interessante é que os commuters masculinos beneficiam-se mais dos movimentos pendulares de longa distância, em termos de resultados econômicos, comparativamente às mulheres. Contrapondo-se em certa medida a ideia do caráter temporário dos movimentos pendulares defendida por Axisa, Scott e Newbold (2012), Sandow e Westin (2010), os resultados do estudo em foco corroboram deslocamentos pendulares de longa distância como uma escolha estratégica de mobilidade para as famílias, e não apenas uma solução de curto prazo.

$\mathrm{Na}$ literatura nacional, poucos estudos analisaram os movimentos pendulares associando-os aos processos migratórios. Soares (2006), por exemplo, analisou os deslocamentos populacionais nos municípios de Belo Horizonte e de Contagem, abordando movimentos migratórios intrametropolitanos e movimentos pendulares por motivo de trabalho. Utilizando dados dos Censos Demográficos de 1991 e 2000 e da Pesquisa de Origem e Destino em 2001, esse autor fez uma análise exploratória, em que seus resultados apontam que, dos indivíduos que residem em Contagem e realizam os movimentos pendulares para Belo Horizonte, $68 \%$ eram emigrantes de Belo Horizonte, em 2001. Assim, seus achados indicam a existência de uma possível relação entre migração e mobilidade pendular.

Magalhães e Rios Neto (2004), de maneira semelhante, estudaram os movimentos pendulares por motivo de trabalho em Belo Horizonte por meio de regressão logística multinível. O objetivo central dos autores foi investigar a importância de características socioeconômicas e domiciliares sobre a duração do tempo de residência. Diversos resultados foram encontrados na pesquisa, entretanto, no tocante ao deslocamento pendular, percebeu-se que, dentre os chefes de família que se deslocam para trabalhar, quanto menor for 
o tempo gasto no trajeto residência-local de trabalho, maior será a chance dele permanecer no mesmo domicílio por um tempo igual ou superior a cinco anos.

Miranda e Domingues (2010), com base nos dados da pesquisa Origem-Destino de 2001 da Fundação João Pinheiro, também investigaram o movimento pendular por motivo de trabalho na Região Metropolitana de Belo Horizonte, através de uma abordagem multinivel. Os autores modelaram o tempo gasto no deslocamento ao trabalho como função de uma série de características individuais, domiciliares e regionais. Seus principais resultados apontam que as mulheres costumam trabalhar mais próximas de suas residências; o acréscimo no tempo de commuting é significativamente maior para os usuários de transporte público comparativamente a outros meios de transporte motorizados; a diferenciação de gênero afeta de maneira distinta o tempo alocado nos movimentos pendulares na região metropolitana de Belo Horizonte; e famílias com filhos que ainda são crianças acabam fixando residências mais próximas ao local de trabalho.

Betarelli Junior (2010) utilizou os microdados provenientes da Pesquisa Nacional por Amostra de Domicílios (PNAD) do IBGE para o ano de 2007, para analisar o quanto as características individuais, familiares e de contexto geográfico podem influenciar a probabilidade de o trabalhador ter maior ou menor custo de acessibilidade no deslocamento da sua residência ao local de trabalho. Para tanto, o referido autor utilizou o "tempo médio ordenado gasto no percurso domicílio-local de trabalho" como proxy do custo de acessibilidade, e através de um modelo Logit Ordenado Generalizado (MLOG), foram investigados os determinantes desse tempo de deslocamento. Os resultados desse estudo sugerem que, na medida em que a idade aumenta, a chance de os indivíduos se preocuparem com os seus custos de acessibilidade também se eleva, e quando esses indivíduos ocupados recebem auxílio de transporte, aumentam também a probabilidade de se gastar até 30 minutos no trajeto entre sua residência e o trabalho.

A despeito das evidências reportadas sobre os determinantes da mobilidade pendular no Brasil, é importante ressaltar que o tema ainda é pouco explorado na literatura nacional. Há, portanto, várias lacunas a serem tratadas, especialmente na investigação da diferença de mo- 
bilidade pendular entre migrantes e não migrantes. Nesse contexto, pesquisas sobre movimentos migratórios costumam levar em conta uma possível existência de seletividade associada a esse grupo de trabalhadores. Vários estudos empíricos registram evidências de que os migrantes são positivamente selecionados, isto é, eles parecem ser, em média, mais habilidosos, motivados, perseverantes, empreendedores comparativamente aos não migrantes (CHISWICK,1999; DOS SANTOS JÚNIOR; MENEZES-FILHO; FERREIRA, 2005; FREGUGLIA, 2007).

O trabalho de Dos Santos Júnior, Menezes-Filho e Ferreira (2005), por exemplo, foi um estudo pioneiro na investigação do viés de seletividade do processo de migração no Brasil. Utilizando os dados da PNAD de 1999, os autores demonstram que os migrantes interestaduais ganham mais, em média, comparativamente aos não migrantes, corroborando a hipótese de que os migrantes são um grupo positivamente selecionado no Brasil.

Apesar de a questão da seletividade ter sido bastante explorada na literatura de migração, ainda se tem tratado pouco desse problema no contexto de mobilidade pendular. Se o grupo de migrantes possui habilidades inatas superiores ao grupo de não migrantes, as decisões de mobilidade pendular podem ser distintas entre esses grupos. $\mathrm{Ou}$ seja, as realocações de local de residência e de local de trabalho frente a alterações de fatores relacionados aos mercados de transporte, trabalho e residencial, podem ser discriminadas por diferenças em habilidades inatas, as quais tendem a favorecer o grupo de migrantes em termos de salário, acesso a informações sobre postos de emprego e acesso a redes sociais em distintas localidades (ZAX, 1994; TROSHCHENKOV, 2012).

Neste contexto, Huber (2014) estudou movimentos pendulares em 15 países da União Europeia. Seus achados empíricos indicaram que os trabalhadores pendulares são mais jovens e têm nível educacional mais elevado comparativamente àqueles que não realizam o deslocamento pendular, na maioria dos países. Assim, Huber (2014) conclui que os trabalhadores pendulares são positivamente selecionados, principalmente em trajetos que envolvem curtas distâncias. 
Troshchenkov (2012) também tentou compreender se há um processo de autosseleção atrelado aos deslocamentos pendulares, ressaltando que a decisão pela realização de tais movimentos pode estar associada a características não observáveis - tais como redes sociais, condições especiais familiares ou talento não observado -, ou, por outro lado, a decisão de ser um trabalhador pendular pode basear-se diretamente no rendimento anterior desse indivíduo. $\mathrm{O}$ autor conclui que o rendimento passado desempenha um papel significativo na decisão pelo deslocamento pendular, evidenciando que os trabalhadores pendulares são positivamente selecionados com base nas características observáveis.

\section{Mobilidade pendular na RMR: fatos observados}

Criada pela Lei Complementar Federal n ${ }^{0} 14$ de 1973, a Região Metropolitana do Recife (RMR) registrou em 2010 cerca de 3,7 mi1hões de habitantes ou o equivalente a $1,9 \%$ da população brasileira no mesmo período. A RMR é composta por 14 municípios, a saber: Abreu e Lima, Araçoiaba, Cabo de Santo Agostinho, Camaragibe, Igarassu, Ipojuca, Ilha de Itamaracá, Itapissuma, Jaboatão dos Guararapes, Moreno, Olinda, Paulista, Recife, São Lourenço da Mata.

A Tabela 1 fornece informações adicionais sobre os indicadores socioeconômicos dos municípios que compõem a RMR. Os municípios de Olinda e Recife registram, respectivamente, densidades demográficas 9 e 7 vezes superior à média da RMR. Apenas a cidade de Recife responde por cerca de $49 \%$ do Produto Interno Bruto (PIB) da área metropolitana e $31 \%$ da riqueza produzida no estado de Pernambuco. Os municípios de Ipojuca e de Jaboatão dos Guararapes aparecem em seguida em termos de PIB, isto é, produzem $14 \%$ e $13 \%$ do PIB da RMR sequencialmente. 
Tabela 1 - Indicadores socioeconômicos dos municípios da RMR - 2010

\begin{tabular}{lcccccc}
\hline Município & Área (Km2) & $\begin{array}{c}\text { População } \\
\text { (hab.) }\end{array}$ & $\begin{array}{c}\text { Densidade } \\
\text { Demográfica }\end{array}$ & IDH & PIB (R\$ mil) & $\begin{array}{c}\text { PIB per } \\
\text { capita } \\
(\mathrm{R} \$)\end{array}$ \\
\hline Abreu e Lima & 126,193 & 94.429 & 724,9 & 0,679 & 847.757 & $8.977,82$ \\
Araçoiaba & 96,381 & 18.156 & 196,74 & 0,592 & 64.421 & $3.550,52$ \\
Cabo de Santo Agostinho & 448,735 & 185.025 & 414,32 & 0,686 & 4.476 .233 & $24.179,78$ \\
Camaragibe & 51,257 & 144.466 & $2.821,93$ & 0,692 & 756.792 & $5.237,10$ \\
Igarassu & 305,56 & 102.021 & 333,88 & 0,665 & 1.146 .753 & $11.244,11$ \\
Ipojuca & 527,107 & 80.637 & 151,39 & 0,619 & 9.095 .145 & $112.924,25$ \\
Ilha de Itamaracá & 66,684 & 21.884 & 328,18 & 0,653 & 121.621 & $5.417,67$ \\
Itapissuma & 74,235 & 23.769 & 320,19 & 0,633 & 479.402 & $20.208,33$ \\
Jaboatão dos Guararapes & 258,694 & 644.620 & $2.493,06$ & 0,717 & 8.359 .552 & $12.966,60$ \\
Moreno & 196,072 & 56.696 & 289,16 & 0,652 & 303.743 & $5.350,70$ \\
Olinda & 41,681 & 377.779 & $9.068,36$ & 0,735 & 3.108 .010 & $8.275,69$ \\
Paulista & 97,312 & 300.466 & $3.086,01$ & 0,732 & 2.129 .675 & $7.084,49$ \\
Recife & 218,435 & 1.537 .704 & $7.037,61$ & 0,772 & 30.032 .003 & $19.540,20$ \\
São Lourenço da Mata & 262,106 & 102.895 & 392,49 & 0,653 & 522.070 & $5.070,81$ \\
\hline RMR & $2.770,45$ & 3.690 .547 & $1.332,11$ & 0,734 & 61.443 .177 & $16.658,36$ \\
Pernambuco & $98.148,323$ & 8.796 .448 & 89,62 & 0,673 & 95.186 .714 & $10.821,55$ \\
\hline
\end{tabular}

Fonte: Elaboração própria a partir de dados do IBGE e PNUD.

Em relação ao Índice de Desenvolvimento Humano (IDH), destacam-se, em termos de maior valor, os municípios de Recife, Olinda, Paulista e Jaboatão dos Guararapes, especialmente o primeiro, cujo IDH é bem superior à média da RMR e do estado de Pernambuco. Já os municípios com maiores PIB per capita podem ser destacados na seguinte ordem: Ipojuca, Cabo de Santo Agostinho, Itapissuma e Recife, todos com valores superiores à média da RMR e Pernambuco. Ipojuca, por exemplo, registra PIB per capita 7 vezes superior ao da RMR.

A RMR abriga o Complexo Industrial e Portuário de Suape e o Porto Digital. O Porto Digital trata-se de um Arranjo Produtivo de Tecnologia da Informação, Comunicação e Economia Criativa situado na cidade do Recife, formado essencialmente por pequenas e médias empresas da própria cidade, mas ao mesmo tempo abrange grandes instituições multinacionais e brasileiras - tais como Accenture, IBM, Microsoft - e projetos de Pesquisa e Desenvolvimento (P\&D) em parceria com Motorola, Samsung, LG e HP. O Complexo Industrial e Portuário de Suape, por sua vez, localiza-se nos municípios de Ipojuca e Cabo de Santo Agostinho. Dentre as empresas em operação, pode-se destacar a Refinaria Abreu e Lima, Estaleiro Atlântico 
Sul, Companhia Brasileira de Petróleo Ipiranga, Amanco, Pamesa, Pepsico, Bunge, Coca-Cola, Unilever e Condor.

A Tabela 2 apresenta as rotas da mobilidade pendular na RMR, conforme os dados do Censo Demográfico de 2010.

Tabela 2 - Matriz de origem e destino dos movimentos pendulares por motivo de trabalho na RMR - 2010

\begin{tabular}{|c|c|c|c|c|c|c|c|c|c|c|c|c|c|c|c|}
\hline \multirow{2}{*}{ Reside } & \multicolumn{15}{|c|}{ Trabalha } \\
\hline & (1) & (2) & (3) & (4) & (5) & (6) & (7) & (8) & (9) & (10) & (11) & (12) & (13) & (14) & $(15)$ \\
\hline Abreu e Lima (1) & & 15 & 242 & 206 & 1.373 & 45 & 45 & 282 & 511 & 25 & 1.168 & 2.824 & 8.850 & 33 & 15.619 \\
\hline$\%$ & & 0,1 & 1,5 & 1,3 & 8,8 & 0,3 & 0,3 & 1,8 & 3,3 & 0,2 & 7,5 & 18,1 & 56,7 & 0,2 & 100,0 \\
\hline Araçoiaba (2) & 23 & & 10 & 25 & 1.022 & 0 & 6 & 9 & 9 & 0 & 9 & 25 & 162 & 4 & 1.304 \\
\hline & 1,8 & & 0,8 & 1,9 & 78,4 & 0,0 & 0,5 & 0,7 & 0,7 & 0,0 & 0,7 & 1,9 & 12,4 & 0,3 & 100,0 \\
\hline C. S. Agostinho (3) & 22 & 0 & & 13 & 0 & 5.804 & 0 & 11 & 3.793 & 38 & 143 & 48 & 4.230 & 0 & 14.102 \\
\hline$\%$ & 0,2 & 0,0 & & 0,1 & 0,0 & 41,2 & 0,0 & 0,1 & 26,9 & 0,3 & 1,0 & 0,3 & 30,0 & 0,0 & 100,0 \\
\hline Camaragibe (4) & 98 & 24 & 285 & & 98 & 93 & 17 & 23 & 1.091 & 7 & 649 & 260 & 22.170 & 981 & 25.796 \\
\hline$\%$ & 0,4 & 0,1 & 1,1 & & 0,4 & 0,4 & 0,1 & 0,1 & 4,2 & 0,0 & 2,5 & 1,0 & 85,9 & 3,8 & 100,0 \\
\hline Igarassu (5) & 1.187 & 76 & 139 & 59 & & 33 & 93 & 524 & 274 & 9 & 813 & 1.587 & 4.487 & 35 & 9.316 \\
\hline$\%$ & 12,7 & 0,8 & 1,5 & 0,6 & & 0,4 & 1,0 & 5,6 & 2,9 & 0,1 & 8,7 & 17,0 & 48,2 & 0,4 & 100,0 \\
\hline Ipojuca (6) & 0 & 0 & 403 & 0 & 0 & & 0 & 0 & 48 & 0 & 0 & 0 & 187 & 0 & 638 \\
\hline$\%$ & 0,0 & 0,0 & 63,2 & 0,0 & 0,0 & & 0,0 & 0,0 & 7,5 & 0,0 & 0,0 & 0,0 & 29,3 & 0,0 & 100,0 \\
\hline racá (7) & 65 & 0 & 24 & 21 & 161 & 8 & & 111 & 18 & 0 & 53 & 33 & 528 & 5 & 1.027 \\
\hline & 6,3 & 0,0 & 2,3 & 2,0 & 15,7 & 0,8 & & 10,8 & 1,8 & 0,0 & 5,2 & 3,2 & 51,4 & 0,5 & 100,0 \\
\hline Itapissuma (8) & 49 & 10 & 21 & 0 & 801 & 9 & 484 & & 38 & 0 & 146 & 170 & 766 & 0 & 2.494 \\
\hline$\%$ & 2,0 & 0,4 & 0,8 & 0,0 & 32,1 & 0,4 & 19,4 & & 1,5 & 0,0 & 5,9 & 6,8 & 30,7 & 0,0 & 100,0 \\
\hline J. Guararapes (9) & 194 & 19 & 5.773 & 183 & 152 & 2.883 & 35 & 0 & & 301 & 1.492 & 764 & 76.552 & 157 & 88.505 \\
\hline$\%$ & 0,2 & 0,0 & 6,5 & 0,2 & 0,2 & 3,3 & 0,0 & 0,0 & & 0,3 & 1,7 & 0,9 & 86,5 & 0,2 & 100,0 \\
\hline Moreno (10) & 0 & 0 & 405 & 15 & 34 & 133 & 0 & 0 & 1.365 & & 96 & 18 & 3.483 & 8 & 5.557 \\
\hline \% & 0,0 & 0,0 & 7,3 & 0,3 & 0,6 & 2,4 & 0,0 & 0,0 & 24,6 & & 1,7 & 0,3 & 62,7 & 0,1 & 100,0 \\
\hline Olinda (11) & 647 & 0 & 712 & 169 & 429 & 262 & 43 & 39 & 2.204 & 34 & & 3.416 & 55.094 & 128 & 63.177 \\
\hline$\%$ & 1,0 & 0,0 & 1,1 & 0,3 & 0,7 & 0,4 & 0,1 & 0,1 & 3,5 & 0,1 & & 5,4 & 87,2 & 0,2 & 100,0 \\
\hline Paulista (12) & 1.815 & 20 & 630 & 127 & 1.111 & 283 & 40 & 227 & 1.873 & 0 & 9.874 & & 39.058 & 116 & 55.174 \\
\hline$\%$ & 3,3 & 0,0 & 1,1 & 0,2 & 2,0 & 0,5 & 0,1 & 0,4 & 3,4 & 0,0 & 17,9 & & 70,8 & 0,2 & 100,0 \\
\hline Recife (13) & 744 & 0 & 3.616 & 2.141 & 920 & 2.595 & 117 & 237 & 13.413 & 252 & 7.387 & 2.797 & & 555 & 34.774 \\
\hline & 2,1 & 0,0 & 10,4 & 6,2 & 2,6 & 7,5 & 0,3 & 0,7 & 38,6 & 0,7 & 21,2 & 8,0 & & 1,6 & 100,0 \\
\hline $\begin{array}{l}\text { São L. da Mata } \\
\text { (14) }\end{array}$ & 20 & 12 & 231 & 1.493 & 48 & 41 & 0 & 0 & 569 & 41 & 329 & 54 & 10.888 & & 13.726 \\
\hline$\%$ & 0,1 & 0,1 & 1,7 & 10,9 & 0,3 & 0,3 & 0,0 & 0,0 & 4,1 & 0,3 & 2,4 & 0,4 & 79,3 & & 100,0 \\
\hline Total (15) & 4.864 & 176 & 12.491 & 4.452 & 6.149 & 12.189 & 880 & 1.463 & 25.206 & 707 & 22.159 & 11.996 & 226.455 & 2.022 & 331.209 \\
\hline$\%$ & 1,5 & 0,1 & 3,8 & 1,3 & 1,9 & 3,7 & 0,3 & 0,4 & 7,6 & 0,2 & 6,7 & 3,6 & 68,4 & 0,6 & 100,0 \\
\hline
\end{tabular}

Fonte: Elaboração própria a partir dos microdados do Censo Demográfico de 2010.

Nota: Apenas trabalhadores que reportaram trajeto diário casa-trabalho entre municípios distintos. Os resultados foram calibrados para o universo a partir dos pesos amostrais.

É possível observar a situação de destaque da capital Recife no processo de acolhimento da força de trabalho pendular. Nota-se que, do total de trabalhadores pendulares na RMR, cerca de 68,4\% (226.455) dirigem-se para o referido município. Os municípios de Olinda (87,2\%), Jaboatão dos Guararapes $(86,5 \%)$, Camaragibe $(85,9 \%)$ e São Lourenço da Mata $(79,3 \%)$ são aqueles onde há o maior percentual de pendulares que se direcionam para trabalhar na capital pernambucana. Na Figura 1 pode-se visualizar que esses municípios são vizinhos (compartilham fronteiras e/ou possuem 
menores distâncias rodoviárias) à cidade do Recife. Além disso, fica perceptível que as localidades vizinhas à capital pernambucana são aquelas que registram maior importância em termos de fluxo pendular para o Recife (ver Índice de Mobilidade Pendular).

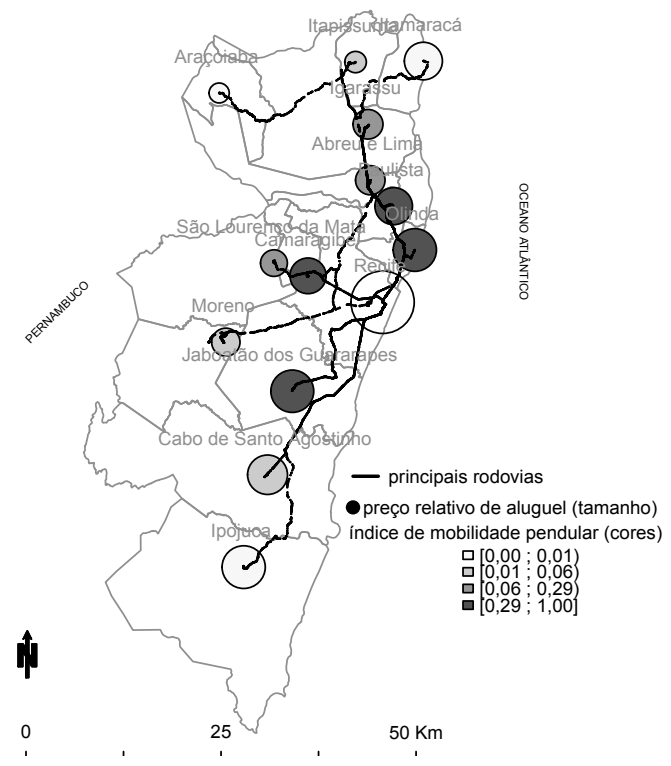

Figura 1 - Mobilidade pendular para Recife: correlações com acessibilidade e custos de habitação

Fonte: Elaboração própria a partir dos microdados do Censo Demográfico de2010edados do Google.

Nota: Apenas trabalhadores que reportaram trajeto diário casa-trabalho direcionado à cidade do Recife. O valor relativo de aluguel refere-se ao valor médio de aluguel residencial no município de residência dividido pelo valor médio de aluguel residencial na capital Recife. O índice de mobilidade pendular foi obtido com a normalização dos fluxos dirigidos ao Recife, ou seja, relativizando o fluxo total do município i para Recife pelo fluxo máximo direcionado a mesma capital. Os resultados foram calibrados para o universo a partir da variável de peso amostral.

Os dados da Tabela 2 também mostram que Jaboatão dos Guararapes é o segundo município com maior absorção de trabalhadores pendulares, isto é, 7,6\% (25.206) dos commuters da RMR trabalham nesta localidade. Esse contingente é principalmente oriundo de Recife $(38,6 \%)$, Cabo de Santo Agostinho (26,9\%) e Moreno $(24,6 \%)$ - ficando evidente, novamente, a importância da proximidade entre os municípios nas rotas dos movimentos pendulares por motivo de trabalho. Em seguida, destaca-se Olinda, que recebe 6,7\% (22.159) de mão de obra pendular. Por outro lado, o município de Araçoiaba é o que recebe o menor percentual de pendulares da área 
metropolitana de análise (176 indivíduos, equivalente a 0,1\%), provavelmente devido a sua localização mais afastada e economia pouco desenvolvida.

Outros aspectos pontuais também chamam a atenção na Tabela 2. Primeiro, $63,2 \%$ dos trabalhadores pendulares que residem em Ipojuca trabalham em Cabo de Santo Agostinho, ao passo que, 41,2\% dos pendulares de Cabo de Santo Agostinho dirigem-se para Ipojuca. Esses elevados percentuais bilaterais estão possivelmente associados aos fluxos de trabalhadores do Complexo Industrial e Portuário de Suape. Segundo, é possível observar o elevado percentual de residentes de Itapissuma que trabalham em Igarassu (32,1\%); dado provavelmente relacionado à proximidade dos dois municípios, assim como pelo maior centro comercial e número de indústrias de Igarassu. Terceiro, destaca-se o caso de Araçoiaba, onde 78,4\% dos trabalhadores pendulares dirigem-se diariamente para o município vizinho de Igarassu. Destarte, Araçoiaba se revela como o único município da RMR no qual a maior proporção de fluxos pendulares é destinada para um município distinto da capital pernambucana.

A elevada absorção de mão de obra flutuante por parte da capital pernambucana possivelmente está relacionada ao fato de o preço relativo de aluguel ser mais elevado no Recife, comparativamente aos demais municípios da RMR, e/ou a maior facilidade de acesso em razão da existência de importantes rodovias que ligam Recife às demais localidades (ver Figura 1). Os elevados custos de habitação na localidade central atuam como uma força de repulsão, incentivando os indivíduos a morarem em localidades mais afastadas e, assim, assumirem os custos da pendularidade (BRUECKNER, 1987).

A Figura 2 evidencia algumas relações entre fluxos pendulares e variáveis teóricas dos modelos de economia urbana (MUTH, 1969; MILLS, 1972). Os dados reforçam a existência de uma relação negativa entre os movimentos pendulares bilaterais e a distância envolvida no movimento casa-trabalho, por um lado, e, por outro, sugerem sensível relação positiva entre mobilidade pendular e preço de habitação no município de trabalho (ver Figura 2(a) e (b), respectivamente). Dessa forma, os dados são bastante sugestivos quanto ao papel dos custos de transporte, acessibilidade e mercado habitacional no processo de mobilidade pendular. Quanto maior (menor) a distância ou tempo de deslocamento entre o município de residência e o 
município de trabalho, menor (maior) o fluxo pendular. Ademais, nota-se que, em média, fluxos pendulares maiores entre a cidade de residência e a cidade de trabalho estão associados a uma maior razão entre o preço médio de aluguel domiciliar no município de trabalho relativamente ao município dormitório.

Figura 2 - Correlações entre movimento pendular, acessibilidade, custos de habitação e migrações intrametropolitanas - RMR - 2010

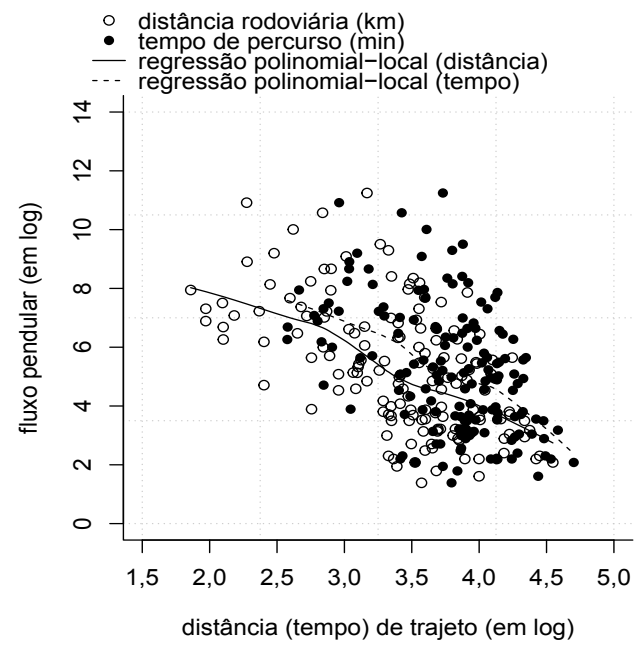

Figura 2(a) - Relação entre fluxos pendulares e distância rodoviária (tempo) de trajeto entre origem (cidade de residência) e destino (cidade de trabalho)

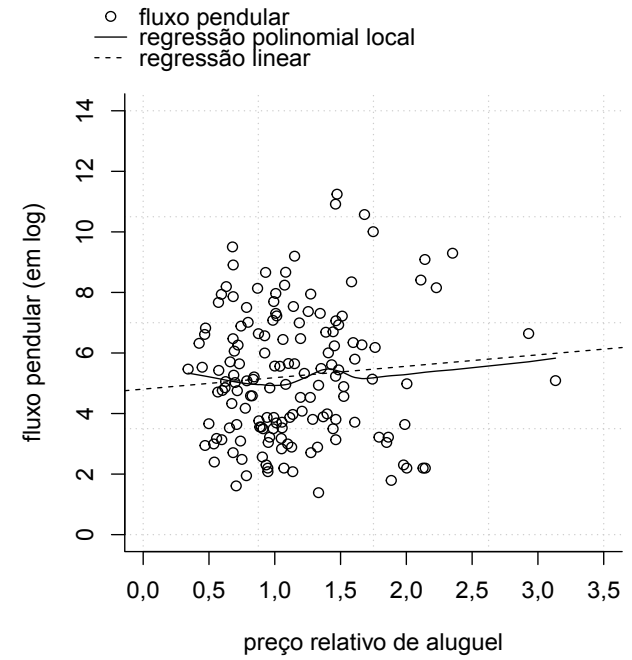

Figura 2(b) - Relação entre fluxos pendulares e preço relativo de aluguel (cidade de trabalho/cidade de residência) 


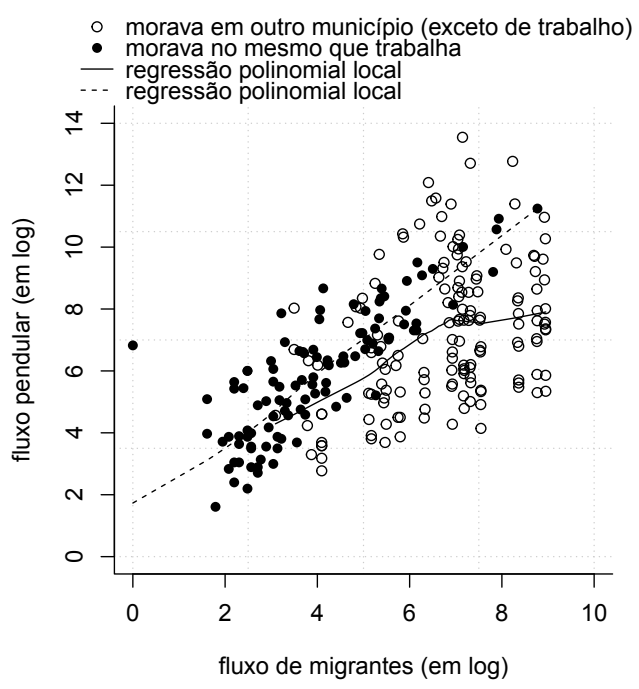

Figura 2(c) - Relação entre fluxos pendulares e fluxos migratórios intrametropolitanos

Fonte: Elaboração própria a partir dos microdados do Censo Demográfico de 2010 e dados do Google.

Nota: Apenas trabalhadores que reportaram trajeto diário casa-trabalho entre municípios distintos. Os fluxos migratórios bilaterais foram definidos com base no critério de data fixa, isto é, são pessoas que em 2005 residiam em um município distinto daquele que afirmaram residir em 2010, dentro da RMR (migrantes recentes intrametropolitanos). O preço relativo de aluguel foi calculado pelo quociente entre o valor médio de aluguel residencial na cidade de trabalho e o valor na cidade de residência (denominador). Os resultados foram calibrados para o universo a partir da variável de peso amostral.

Na Figura 2(c), observa-se uma relação positiva entre os fluxos pendulares bilaterais e movimentos migratórios intrametropolitanos na RMR. Essa associação é percebida tanto quando se consideram as pessoas que em 2005 moravam em outro município diferente daquele de trabalho em 2010 (indivíduos que mudaram de residência e podem ou não ter mudado o município de trabalho), como para aqueles que em 2005 moravam no município que estavam trabalhando em 2010 (indivíduos que provavelmente mudaram apenas de residência). Assim, os dados sugerem que as escolhas de local de trabalho e de local de residência não deveriam ser tratadas de forma independente. Ao contrário, a partir das trocas bilaterais na RMR percebe-se que, em média, um município "A" que entre 2005-2010 registrou forte absorção de pessoas que residiam no município "B" (fluxo de imigrantes), em 2010 enviava diariamente um grande fluxo de trabalhadores pendulares para esse último município (troca de 
local de residência com manutenção do local de trabalho). Da mesma forma, se o município "A" receber grande contingente de pessoas que há cinco anos residiam em um município distinto de $B$, também tende a emitir muitos trabalhadores pendulares para " $\mathrm{B}$ " (troca de local de residência com possível troca de local de trabalho). ${ }^{5} \mathrm{Ou}$ seja, municípios que recebem maior quantitativo de novos residentes também tendem a direcionar maiores fluxos de trabalhadores pendulares, sobretudo para o município de procedência desses imigrantes.

Em linhas gerais, os dados supracitados fornecem pistas importantes sobre possíveis relações entre movimentos pendulares na RMR, migrações intrametropolitanas, mercado habitacional e sistema de mobilidade urbana.

\section{Estratégia empírica}

A estratégia empírica adotada neste estudo busca identificar quais variáveis socioeconômicas e locacionais são relevantes na discriminação da escolha individual de local de trabalho fora do município de residência (decisão de commuting). No entanto, uma questão importante a ser investigada é se trabalhadores com histórico recente de migração intrametropolitana são mais propensos a trabalhar em um município distinto daquele de residência quando comparado aos não migrantes. Ou seja, a decisão de mudança de residência é uma escolha complementar ou substituta em relação à decisão de local de trabalho?

Nesse contexto, vale notar que, no Brasil, há evidências de que os migrantes são distribuídos de forma aleatória na população, isto é, são, em média, mais propensos ao risco, motivados, perseverantes em relação aos não migrantes (DOS SANTOS JÚNIOR; MENEZESFILHO; FERREIRA, 2005). Portanto, ignorar possíveis diferenças entre migrantes e não migrantes em habilidades inatas poderia produzir estimativas tendenciosas acerca dos parâmetros envolvidos na decisão de mobilidade pendular (HECKMAN, 1979).

\footnotetext{
5 Os dados do Censo Demográfico não permitem identificar em que município o indivíduo trabalhava há cinco anos da data de entrevista, apenas o município onde residia.
} 
Outra questão relevante diz respeito às possíveis inter-relações teóricas entre as decisões de local de trabalho e de residência. Zax (1994), por exemplo, faz uma extensão dos modelos clássicos da literatura especializada em que a maximização do bem-estar individual depende de escolhas de commuting e de migração (mudança de residência), as quais afetam da jornada até o trabalho por meio de impactos sobre custos de mobilidade e sobre a disponibilidade de tempo para o lazer. $\mathrm{O}$ autor demonstra que realocações de residência e de local de trabalho podem ocorrer de forma simultânea a depender do diferencial de bem-estar relacionado a mudanças exógenas em fatores atrelados aos mercados de trabalho, residencial e de transporte. Ademais, seu modelo prediz que a decisão de mudança residencial em esferas inter-regionais é complementar à decisão de commuting, isto é, a migração está atrelada a uma realocação do local de trabalho.

\subsection{Modelo econométrico}

No intuito de identificar se há relação entre migração intrametropolitana e mobilidade pendular na RMR, adota-se um modelo de resultados potenciais (efeito-tratamento endógeno), onde a variável de resultado é a decisão de mobilidade pendular. Assume-se um processo de seleção prévia (não aleatória) entre migrantes e não migrantes (decisão de mudança de residência) correlacionado com variáveis não observadas que afetam a mobilidade pendular (autosseleção endógena). Os migrantes intrametropolitanos representam o grupo tratado (grupo que efetivamente mudou de residência), enquanto os não migrantes representam o grupo de controle (grupo que poderia ter mudado de residência). O sistema de equações abaixo resume o modelo empírico:

$$
\begin{aligned}
& y_{1}^{*}=\beta_{1}{ }^{\prime} x+\alpha y_{2}+\varepsilon_{1} \\
& y_{2}^{*}=\beta_{2}{ }^{\prime} z+\varepsilon_{2}
\end{aligned}
$$

Onde $y_{1}^{*}$ e $y_{2}^{*}$ são variáveis latentes (contínuas e não observadas) que mensuram os benefícios líquidos gerados pelas decisões de mobilidade pendular (escolha de local de trabalho) e de migração 
(escolha de local de residência), respectivamente. O vetor $x$ inclui variáveis exógenas que representam características socioeconômicas, domiciliares e locacionais, enquanto o vetor $Z$ engloba as mesmas covariadas em $x$ e ao menos uma outra variável relacionada à decisão de migração (restrição de exclusão); $\beta_{1}$ e $\beta_{2}$ são vetores de parâmetros; $\alpha$ é um parâmetro estrutural que relaciona deslocamento pendular à decisão de mudança de residência (migração) e $\varepsilon_{1} \mathrm{e}$ $\varepsilon_{2}$ são termos randômicos correlacionados. Por exemplo, caso seja estatisticamente constatado que $\alpha>0$, há evidência de que as decisões de mudança de residência e mobilidade pendular no contexto intermunicipal são complementares (RENKOW; HOOVER, 2000).

Note-se que a estimativa isolada da Equação (1) - equação de resultado -, isto é, desconsiderando um processo endógeno de autosseleção entre migrantes e não migrantes, poderia produzir resultados tendenciosos, haja vista que $y_{1}^{*}$ e $\varepsilon_{1}$ seriam correlacionadas em uma amostra não aleatória ${ }^{6}$. Ao contrário, a incorporação da Equação (2) - equação de seleção -, correlacionada em variáveis não observadas (1), permite uma estimativa não enviesada de $\alpha$, e, por conseguinte, inferir se trabalhadores que anteriormente residiam em outro município são mais ou menos propensos à mobilidade pendular comparados aqueles que nasceram e sempre moraram no mesmo município.

Considere $y_{1}$ e $y_{2}$ variáveis binárias que representam as realizações de $y_{1}^{*}$ e $y_{2}^{*}$, respectivamente. Ademais, $y_{1}$ recebe o valor 1 se o trabalhador opta pela mobilidade pendular - escolhe uma cidade de trabalho distinta da cidade de residência $\left(y_{1}^{*}>0\right)$ e 0 caso contrário $\left(y_{1}^{*} \leq 0\right)$, enquanto $y_{2}$ é igual a 1 se o indivíduo é migrante - escolhe residir em outra cidade $\left(y_{2}^{*}>0\right)$ e 0 caso seja não migrante - não altera o local de residência $y_{2}^{*} \leq 0$. Desse modo, a probabilidade conjunta de se observar um trabalhador que alterou tanto o local de trabalho e quanto o local de residência $y_{1}=y_{2}=1$ é dada por:

$$
\operatorname{Pr}\left(y_{1}=1, y_{2}=1\right)=C\left(\Phi\left(y_{1 i}=1\right), \Phi\left(y_{2 i}=1\right) ; \theta\right)
$$

Onde $\Phi$ é a função de distribuição acumulada normal; $\theta$ é um parâmetro que mensura a dependência entre as distribuições marginais dos termos estocásticos $\varepsilon_{1}$ e $\varepsilon_{2}$; $C$ é uma função cópula (bidimensional) que combina as referidas distribuições $\Phi\left(\varepsilon_{1}\right)$ e $\Phi\left(\varepsilon_{2}\right)$.

\footnotetext{
${ }^{6}$ Um processo de autosseleção amostral pode gerar viés de endogeneidade, uma vez que a variável de tratamento pode se correlacionar com variáveis omitidas que determinam a variável de resultado potencial (HECKMAN; NAVARRO-LOZANO, 2004).
} 
O uso de funções cópulas permite manter a eficiência paramétrica na estimação do sistema (1)--(2) e relaxar a hipótese de distribuição normal conjunta de $\varepsilon_{1}$ e $\varepsilon_{2}$ (WINKELMANN, 2012; RADICE; MARRA; WOJTYS, 2013). Existem diferentes classes de cópulas com distintos critérios de agrupamentos de distribuições marginais. ${ }^{7}$ Neste estudo, foram consideradas as seguintes famílias usuais de cópulas: (i) a cópula elíptica Gaussiana e (ii) cópulas Arquimedianas - Clayton, Frank, AliMikhail-Haq (AMH), Farlie-Gumbel-Morgenstern (FGM), Gumbel e Joe, cujas equações e intervalos para o parâmetro de dependência podem ser consultadas na Tabela A.2 do apêndice.

No caso das cópulas Gaussiana, FGM e AMH, por exemplo, $\theta \in[1,-1]$ representa o coeficiente de correlação entre variáveis não observadas $\left(\varepsilon_{1}\right.$ e $\left.\varepsilon_{2}\right)$. Dentre as Frank, Joe, Clayton e Gumbel, apenas a Frank permite capturar diretamente estruturas de dependência positiva e negativa. Nas demais, a modelagem de dependência negativa apenas pode ser feita a partir de versões rotacionadas ${ }^{8}$ entre $90^{\circ}$ e $270^{\circ}$. As Figuras a A.1 e A.2 do apêndice ilustram, através de simulações, as características e assimetrias capturadas pelas cópulas reportadas.

As cópulas Gaussiana, Frank, AMH, FGM são simétricas, isto é, não apresentam forte concentração de probabilidade em apenas uma de suas caudas. Contudo, as Frank, FGM e AMH registram maior dependência no meio de sua distribuição comparativamente à Gaussiana, e podem capturar uma estrutura de dependência fraca. Já as cópulas Clayton, Joe e Gumbel têm estrutura assimétrica, todas com forte concentração de probabilidade em uma das suas caudas. ${ }^{9}$ No caso da cópula Joe, por exemplo, percebe-se forte (fraca) depen-

7 Para mais detalhes sobre estimações em cópulas, vide Nelsen (2006) e Brechmann e Schepsmeier (2013).

8 Conforme mostram Brechmann e Schepsmeier (2013), é possível obter versões rotacionadas das cópulas Clayton, Joe e Gumbel a partir das seguintes expressões: $C_{90}(u, v)=v-C(1-u, v)$, $C_{180}(u, v)=u+v-1-C(1-u, 1-v)$, e $C_{270}(u, v)=u-C(u, 1-v)$. onde $C$ é uma função cópula sem rotação $\left(0^{0}\right.$ de rotação) e $u$ e $v$ distribuições marginais.

9 Vale ressaltar que nessas cópulas o parâmetro de dependência não se situa em intervalos comparáveis. No entanto, a estatística de Kendall apresenta uma relação matemática $\theta$ com de modo a facilitar a interpretação e comparação do grau de dependência capturado por diferentes cópulas, situando-se, em geral, no intervalo [1,1]. Por exemplo, $\tau=0$ indica independência entre variáveis aleatórias modeladas na cópula. Quanto mais próximo $\tau$ estiver de -1, mais forte será a associação negativa entre as variáveis de análise e, por outro lado, valores mais próximos de 1 indicam forte dependência positiva. Para a cópula Gaussiana, $\tau$ é dado por $\tau=\frac{\pi}{2} \arcsin \theta$, enquanto nas demais reportadas é calculado por $\tau=1+4 \int_{0}^{1} \frac{\phi(t)}{\left.\phi^{\prime} t\right)} d t$, onde $\phi(t)$ é uma função geradora específica para cada função cópula e $\phi^{\prime}(t)$ é a sua primeira derivada. Para mais detalhes, consultar Brechmann e Schepsmeier (2013, p.8) e Nelsen (2016). 
dência na cauda superior (inferior). Raciocínio análogo se estende para as cópulas Clayton e Gumbel.

A incorporação das funções cópulas na estimação dos parâmetros do modelo (1)--(2) é feita a partir da maximização da seguinte função de log-verossimilhança (WINKELMANN, 2012):

$$
\begin{gathered}
\ell=\sum_{i=1}^{n}\left\{y_{1 i}, y_{2 i} \log \operatorname{Pr}\left(y_{1 i}=1, y_{2 i}=1\right)+y_{1 i}\left(1-y_{2 i}\right) \log \operatorname{Pr}\left(y_{1 i}=1, y_{2 i}=0\right)\right. \\
+\left(1-y_{1 i}\right) y_{2 i} \log \operatorname{Pr}\left(y_{1 i}=0, y_{2 i}=1\right) \\
\left.+\left(1-y_{1 i}\right)\left(1-y_{2 i}\right) \log \operatorname{Pr}\left(y_{1 i}=0, y_{2 i}=0\right)\right\}
\end{gathered}
$$

Onde $\mathrm{i}=1, \ldots, \mathrm{n}$ indexa cada observação na amostra; $\operatorname{Pr}\left(y_{1 i}=1, y_{2 i}=0\right)=\operatorname{Pr}\left(y_{1 i}=1\right)-\operatorname{Pr}\left(y_{1 i}=1, y_{2 i}=1\right) ; \operatorname{Pr}\left(y_{1 i}=0, y_{2 i}=1\right)$ $=\operatorname{Pr}\left(y_{2 i}=1\right)-\operatorname{Pr}\left(y_{1 i}=1, y_{2 i}=1\right) ; \operatorname{Pr}\left(y_{1 i}=0 y_{2 i}=0\right)=1-\left[\operatorname{Pr}\left(y_{1 i}=1\right)+\right.$ $\left.\operatorname{Pr}\left(y_{2 i}=1\right)-\operatorname{Pr}\left(y_{1 i}=1, y_{2 i}=1\right)\right] ; \operatorname{Pr}\left(y_{1 i}=1, y_{2 i}=1\right)=C\left(\Phi\left(-\beta_{1}^{\prime} x-\alpha\right)\right.$, $\left.\Phi\left(-\beta_{2}^{\prime} x\right) ; \theta\right) ; \operatorname{Pr}\left(y_{1 i}=1\right)=\Phi\left(-\beta_{1}^{\prime} x-\alpha\right)$ e $\operatorname{Pr}\left(y_{2 i}=1\right)=\Phi\left(-\beta_{2}^{\prime} x\right)$.

Uma vez que a função cópula e o modelo econométrico sejam bem especificados, a otimização de (4) assegura um vetor parâmetros $\eta=\left(\beta_{1}, \beta_{2}, \alpha, \theta\right)$ consistente e normalmente distribuído em grandes amostras (WINKELMANN, 2012). Ademais, o processo de estimação paramétrica em destaque não exige a presença de restrições geradas por exclusão de variáveis, isto é, que entre as covariadas que compõem a equação de tratamento (2) haja ao menos uma variável não incluída na equação de resultado (1). Ou seja, a estimativa correta do parâmetro estrutural $\alpha$ pode ser obtida por não linearidade na função de verossimilhança, desde que haja bastante variabilidade nas covariadas do modelo (TOOMET; HENNINGSEN, 2008). No entanto, conforme mostram Marra e Radice (2011), o uso de restrições de exclusão ("variáveis instrumentais") pode ajudar na redução de possíveis vieses na estimativa do referido parâmetro estrutural.

$\mathrm{Na}$ prática, não se sabe a priori que função cópula deve ser usada para modelagem da distribuição conjunta de variáveis não observadas. No entanto, o uso de critérios de penalização por parcimônia, a exemplo dos conhecidos critérios de informação de Bayesiano - ou de Schwarz - (BIC) e de Akaike (AIC), permite identificar que cópula melhor se ajusta aos dados a partir da especificação do mo- 
delo empírico (WINKELMANN, 2012; MARRA; RADICE, 2011). Assim, deve-se estimar vários modelos e selecionar aquele com menor valor de critério de informação, em detrimento dos demais. ${ }^{10}$

\subsection{Testes para Escolhas Simultâneas}

O modelo teórico de Zax (1994) considera a possibilidade de realocações simultâneas de local de residência e de local de trabalho frente a choques exógenos em variáveis relacionadas a custos de mobilidade e custos de moradia. No intuito de se averiguar estatisticamente a presença de escolhas simultâneas, testa-se a hipótese de que pares de escolhas (outcomes) são indistinguíveis, isto é, se duas alternativas podem ser combinadas (LONG, 1997). Para tanto, seguindo a intuição de Piracha e Vadean (2010), considere o seguinte modelo de equações simultâneas em que as escolhas de mobilidade pendular dos não migrantes são consideradas como alternativas para os migrantes:

$$
y_{j}^{*}=\beta_{j}^{\prime} z+u_{j}
$$

Onde $y_{j}^{*}$ é uma variável latente referente ao benefício gerado pela escolha $j$ e $u_{j}$ um termo randômico que segue uma distribuição de valor extremo (Gumbel); $\beta_{j}$ é um vetor de parâmetros e $j$ indexa as seguintes escolhas: 1 - não migrar e trabalhar no município de residência; 2 - não migrar e trabalhar em outro município; 3 - migrar e trabalhar no município de residência e 4 - migrar e trabalhar em outro município.

A escolha $k$ é observada se $y_{k}^{*}=\max \left(y_{l}^{*}\right) \forall k \neq l$. Nesse contexto, Cameron e Trivedi (2005) demonstram que a probabilidade $\mathrm{da}$ escolha $\mathrm{k}$ ser observada pode ser estimada a partir de um logit multinomial:

$$
\operatorname{Pr}\left(y_{j}=k\right)=\frac{e^{\beta_{k}^{\prime} z}}{\sum_{j=1}^{4} e^{\beta_{j}^{\prime} z}}
$$

10 As estatísticas AIC e BIC podem ser calculadas, respectivamente, por $A I C=-2 \hat{\ell}+2 k$ e $B I C=-2 \hat{\ell}+\log (n) k$, onde $\hat{l}$ é o valor maximizado da função de log-verossimilhança (4) e $k$ o grau de liberdade do modelo (1)-(2). Ambos os critérios são parcimoniosos, pois penalizam a inclusão de mais variáveis nas estimações. 
A partir da estimativa do modelo multinomial (5) por Máxima Verossimilhança, podem ser realizados testes de especificação de Hausman comparando o modelo de escolhas simultâneas com regressões restritas em que as escolhas de mobilidade pendular dos não migrantes não são escolhas alternativas para o grupo de migrantes (não simultaneidade), isto é, testa-se a hipótese nula de que não há diferença estatística entre os referidos modelos. ${ }^{11}$ Ademais, seguindo Long (1997), também se estimam modelos logit univariados em que a variável de resposta binária representa cada par de alternativas já reportadas. Esse procedimento permite testar a hipótese nula de que todos os coeficientes (exceto o intercepto) são estatisticamente iguais a zero - testes de Wald e de Razão de Verossimilhança (RV), isto é, testa-se se os coeficientes associados a cada par de alternativas são similares (as alternativas de mobilidade pendular dos não migrantes podem ser escolhas para os migrantes). ${ }^{12}$

\subsection{Efeito Médio do Tratamento}

Após o controle para covariadas individuais, locacionais e dependência em variáveis não observadas envolvidas no processo de escolha de locais de residência e de trabalho, a hipótese central é avaliar se a decisão de mudança de residência (migração) é complementar ou substituta da decisão de mudança de local de trabalho (mobilidade pendular). Ou seja, trabalhadores com histórico recente de migração intrametropolitana são mais ou menos propensos à mobilidade pendular comparados aos não migrantes?

Essa investigação pode ser feita por meio de uma estimativa paramétrica da estatística conhecida como Efeito Médio do Tratamento (Average Treatment Effect - ATE). Dada a "aleatorização" do processo de seleção entre migrantes (grupo tratado) e não migrantes (grupo

${ }^{11}$ Por exemplo, o modelo de escolhas simultâneas é comparado com dois modelos alternativos a partir de (5): (i) um modelo restrito ao seguinte subconjunto de escolhas: 1 - não migrar e trabalhar no município de residência e 2 - não migrar e trabalhar em outro município e (ii) outro modelo para as seguintes escolhas: 1 - migrar e trabalhar no município de residência e 2 - migrar e trabalhar em outro município. $O$ teste de especificação de Hausman é calculado por $H=\left(\beta_{F}-\beta_{R}\right)^{\prime}\left(V_{F}-V_{R}\right)^{-1}\left(\beta_{F}-\beta_{R}\right)$, onde $\beta_{F}$ e $\beta_{R}$ são são vetores de parâmetros do modelo (5) em todo conjunto de escolhas e em um subconjunto de escolhas, respectivamente; $V_{F}$ é a matriz de covariância do modelo completo e $V_{R}$ a matriz de covariância do modelo restrito (subconjunto de escolhas). A Estatística $H$ segue uma distribuição Qui-Quadrado.

12 Vide Long (1997) para mais detalhes. 
de controle) a partir da equação de seleção (2), o ATE captura a diferença entre o resultado esperado (probabilidade de mobilidade pendular) quando o tratamento ocorre, isto é, se o indivíduo decide migrar, e o resultado esperado na situação em que o tratamento não ocorre (quando o trabalhador é não migrante).

De acordo com Marra e Radice (2011), o ATE pode ser estimado pela média amostral da seguinte diferença de probabilidades condicionadas:

$A T E=\frac{1}{n} \sum_{i=1}^{n}\left[\operatorname{Pr}\left(y_{1 i}=1 \mid y_{2 i}=1, x_{i}, z_{i}\right)-\operatorname{Pr}\left(y_{1 i}=1, \mid y_{2 i}=0, x_{i}, z_{i}\right)\right]$

Onde $\operatorname{Pr}\left(y_{1 i}=1 \mid y_{2 i}=1, x_{i}, z_{i}\right)=\frac{C\left(\Phi\left(-\beta_{1}^{\prime} x_{1 i}-\alpha\right), \Phi\left(-\beta_{2}^{\prime} z_{2}\right) ; \theta\right)}{\Phi\left(-\beta_{2}^{\prime} z_{2}\right)}$

e $\operatorname{Pr}\left(y_{1 i}=1 \mid y_{2 i}=0, x_{i}, z_{i}\right)=\frac{\Phi\left(-\beta_{1}^{\prime} x_{1 i}\right)-C\left(\Phi\left(-\beta_{1}^{\prime} x_{1 i}\right), \Phi\left(-\beta_{2}^{\prime}\right.\right.}{1-\Phi\left(-\beta_{2}^{\prime} z_{2}\right)}$ e $n$

é o tamanho da amostra.

Ainda é possível estimar a estatística ATE por subgrupos, na tentativa de se capturar efeitos de heterogeneidade. Os intervalos de confiança do ATE podem ser obtidos pelo método Delta. ${ }^{13}$

\section{Base de dados e seleção amostral}

Neste estudo, foram utilizados os microdados do Censo Demográfico 2010. A definição de migrante adotada foi a de data fixa, ou seja, engloba aqueles indivíduos que, há cinco anos, estavam morando em um município da RMR distinto daquele declarado na data da entrevista do Censo. A utilização dessa definição permite identificar migrantes intrametropolitanos (pessoas que mudaram previamente o local de residência) durante o quinquênio 2005-2010. Já o não migrante, foi classificado como o indivíduo que nasceu e sempre morou no município recenseado.

${ }^{13}$ O método Delta é um procedimento para estimação da variância de um estimador derivado da combinação linear. Este procedimento envolve cálculo matricial, no qual através da inversa da matriz de segundas derivadas da função de log-verossimilhança obtém-se a matriz de variâncias-covariâncias. Para maiores detalhes, vide RAO e TOUTENBURG (1999). 
A identificação do indivíduo que realiza o deslocamento pendular (commuter) foi baseada no quesito sobre trajeto unidirecional casatrabalho. Dessa forma, foram considerados commuters aqueles que, na data do recenseamento, afirmaram cruzar diariamente as fronteiras territoriais municipais para trabalhar, enquanto os não commuters foram classificados como aqueles que trabalhavam dentro do município em que residem e que também realizam o trajeto casa-trabalho diariamente. Uma vez que a análise restringiu-se ao ambiente metropolitano, apenas foram considerados trabalhadores da RMR (área urbana), no que se refere tanto ao local de residência, quanto ao local de trabalho.

Ademais, foram excluídos da amostra selecionada indivíduos desocupados na semana do recenseamento, com idade inferior a 25 anos ou superior a 65 anos, estrangeiros, pessoas com alguma deficiência de visão, locomoção, auditiva ou mental, pessoas que frequentavam escola ou universidades e/ou que não realizavam trajetos diários de casa para o local de trabalho. Essa seleção teve o intuito de eliminar migrantes agregados e/ou estudantes (que acompanham outros migrantes - idosos e/ou crianças), filtrando apenas trabalhadores que teriam condições mais apropriadas para decidir sobre migração e mobilidade pendular, tendo em conta fatores de ordem econômica. Após os recortes mencionados, a amostra final totalizou 22.541 residentes no meio urbano da RMR, sendo 6.774 (30\%) trabalhadores pendulares e 15.767 (70\%) de não pendulares, por um lado, e, por outro, $1.830(8,1 \%)$ migrantes intrametropolitanos e 20.711 (91,9\%) não migrantes.

No tocante às variáveis explicativas do modelo empírico (1)-(2), foram selecionados dois grupos de covariadas: (i) variáveis de ordem pessoal/domiciliar: gênero, cor da pele, idade, idade ao quadrado, faixas de instrução, posição de chefia domiciliar, presença de cônjuge, número de crianças no domicílio por faixa etária e número de idosos aposentados/pensionistas no domicílio e; (ii) variáveis locacionais por Área de Ponderação Censitária (APC) de residência, ${ }^{14}$ valor médio de aluguel domiciliar, proporção de domicílios com acesso à

\footnotetext{
${ }^{14}$ As APCs são agrupamentos de setores censitários definidos pelo IBGE para a representatividade da amostra em termos populacionais. Cada área é formada por um agrupamento mutuamente exclusivo de setores censitários contíguos. O tamanho dessas áreas, em termos de número de domicílios, é de 400 domicílios ocupados, excetuando-se aqueles municípios que não atingem este total de domicílios. Para estes últimos, o próprio município é considerado uma área de ponderação. Nos microdados censitários, cada APC é identificada pelo código do estrato.
} 
água encanada, proporção de domicílios com coleta de lixo, proporção de domicílios com acesso à internet, proporção de imigrantes não naturais do município com 6 a 9 anos de residência (restrição de exclusão); quocientes locacionais para os setores de Agricultura, Indústria, Serviços, Social e Administração Pública, ${ }^{15}$ distância rodoviária da APC até o marco zero da capital Recife, ${ }^{16}$ área da APC e variáveis binárias por município de residência. Vale ressaltar que tal conjunto de variáveis é consistente com outros estudos na literatura especializada (ROUWENDAL; RIETVELD, 1994; RENKOW; HOOVER, 2000; PAPANIKOLAOU, 2006; VAN OMMEREN; DARGAY, 2006; AXISA; SCOTT; NEWBOLD, 2012). O Quadro A.l, do apêndice, apresenta uma descrição detalhada de cada variável selecionada.

O uso da variável "proporção de imigrantes não naturais do município com 6 a 9 anos de residência por APC" procura auxiliar na identificação estrutural do modelo empírico e segue a mesma intuição de Renkow e Hoover (2000). Quando usada como restrição de exclusão, ela é retirada da equação (1) e entra apenas nas covariadas da equação de seleção (2). Ou seja, assume-se que a referida variável é uma proxy para o efeito de redes de migrantes (ou redes sociais) e que a mesma tem papel primordial na decisão de migração. Por exemplo, espera-se que quanto maior for a presença de imigrantes na APC de residência de um trabalhador, maior deve ser o acesso do mesmo a informações sobre oportunidades de emprego trazidas pelos novos moradores, característica que poderia estimular a migração (atração) futura de mais trabalhadores.

A Tabela 3 registra estatísticas descritivas da amostra de trabalhadores selecionados segundo características socioeconômicas e locacionais e por condição de movimento pendular.

${ }^{15} \mathrm{O}$ quociente locacional (QL) é uma medida que indica se uma localidade específica possui especialização em determinado setor de atividade econômica. Seu cálculo foi realizado por meio da seguinte fórmula: $Q L=\frac{E_{-} j i / E_{-} j}{\left(E_{R M R i} / E_{R M R}\right)}$, onde $E_{j i}$ é o emprego no setor i na APC j; $E_{j}$ é o emprego total em todos os setores da APC j; $E_{R M R i} \mathrm{o}$ emprego no setor i na RMR e $E_{R M R} \mathrm{O}$ emprego total na RMR.

${ }^{16}$ As distâncias rodoviárias foram obtidas a partir do mapa de malhas digitais provido pelo IBGE - coordenadas geográficas centrais de cada APC -, juntamente com o aplicativo Google Maps e o pacote ggmap do software estatístico $R$. 
Tabela 3 - Estatísticas descritivas da amostra segundo características pessoais, domiciliares e locacionais e por condição de mobilidade pendular dos trabalhadores da RMR - 2010

\begin{tabular}{|c|c|c|}
\hline & $\begin{array}{l}\text { Trabalhador } \\
\text { pendular }\end{array}$ & $\begin{array}{l}\text { Trabalhador } \\
\text { não pendular }\end{array}$ \\
\hline \multicolumn{3}{|l|}{ Gênero - \% } \\
\hline Masculino & 65,9 & 60,7 \\
\hline Feminino & 34,1 & 39,3 \\
\hline Idade (média) & 36,0 & 37,5 \\
\hline \multicolumn{3}{|l|}{ Cor da pele - \% } \\
\hline Branca & 35,4 & 35,6 \\
\hline Preta & 10,7 & 10,3 \\
\hline Parda & 52,7 & 53,1 \\
\hline Amarela/Vermelha & 1,2 & 1,1 \\
\hline \multicolumn{3}{|l|}{ Escolaridade } \\
\hline Sem instrução e fundamental incompleto & 23,1 & 31,1 \\
\hline Fundamental completo e médio incompleto & 14,7 & 14,9 \\
\hline Médio completo e superior incompleto & 48,4 & 39,2 \\
\hline Superior Completo & 13,7 & 14,8 \\
\hline \multicolumn{3}{|l|}{ Domicílio } \\
\hline Chefe & 48,2 & 46,3 \\
\hline Não chefe & 51,8 & 53,7 \\
\hline Vive com cônjuge & 69,1 & 66,8 \\
\hline Não vive com cônjuge & 30,9 & 33,2 \\
\hline Crianças até 5 anos de idade (média) & 0,3 & 0,2 \\
\hline Crianças entre 6 e 9 anos de idade (média) & 0,2 & 0,2 \\
\hline Crianças entre 10 e 14 anos de idade (média) & 0,2 & 0,2 \\
\hline Aposentados com 65 anos ou mais de idade (média) & 0,1 & 0,1 \\
\hline \multicolumn{3}{|l|}{ Condição de migrante (2005-2010) - \% } \\
\hline Migrante & 17,8 & 4,0 \\
\hline Não migrante & 82,2 & 96,0 \\
\hline \multicolumn{3}{|l|}{ Município de residência em 2010 - \% } \\
\hline Abreu e Lima & 4,1 & 1,4 \\
\hline Araçoiaba & 1,4 & 0,6 \\
\hline Cabo de Santo Agostinho & 6,2 & 7,3 \\
\hline Camaragibe & 10,6 & 3,8 \\
\hline Igarassu & 3,6 & 3,0 \\
\hline Ipojuca & 0,2 & 3,1 \\
\hline Itamaracá & 0,8 & 1,2 \\
\hline Itapissuma & 1,0 & 0,6 \\
\hline Jaboatão dos Guararapes & 14,6 & 8,8 \\
\hline Moreno & 2,8 & 1,5 \\
\hline Olinda & 24,6 & 11,3 \\
\hline Paulista & 16,1 & 5,8 \\
\hline Recife & 8,3 & 49,5 \\
\hline São Lourenço da Mata & 5,6 & 2,1 \\
\hline \multicolumn{3}{|l|}{ Variáveis locacionais por APC - médias } \\
\hline Valor de aluguel residencial & 235,1 & 288,2 \\
\hline Proporção de domicílios com água encanada & 0,9 & 0,9 \\
\hline Proporção de domicílios com coleta de lixo & 0,9 & 0,9 \\
\hline Proporção de domicílios com acesso à internet & 0,8 & 0,8 \\
\hline Quociente Locacional - Agricultura & 1,4 & 1,2 \\
\hline Quociente Locacional - Industria & 1,2 & 1,0 \\
\hline
\end{tabular}


Tabela 3 - Estatísticas descritivas da amostra segundo características pessoais, domiciliares e locacionais e por condição de mobilidade pendular dos trabalhadores da RMR - 2010 (Continuação)

\begin{tabular}{lcc}
\hline & $\begin{array}{c}\text { Trabalhador } \\
\text { pendular }\end{array}$ & $\begin{array}{c}\text { Trabalhador } \\
\text { não pendular }\end{array}$ \\
\hline Quociente Locacional - Serviços & 1,0 & 1,0 \\
Quociente Locacional - Social & 0,9 & 1,0 \\
Quociente Locacional - Administração Pública & 0,8 & 1,0 \\
Proporção de migrantes com 6 a 9 anos de residência & 0,4 & 0,3 \\
Área da APC em Km ${ }^{2}$ & 15,3 & 17,8 \\
Distância rodoviária da APC até Recife - Km² & 18,2 & 16,3 \\
\hline Observações & 6.774 & 15.767 \\
\hline
\end{tabular}

Fonte: Elaboração própria a partir dos microdados do Censo Demográfico de 2010 e do Google.

Os dados indicam distinções entre os grupos de trabalhadores não pendulares e pendulares, especialmente em termos de gênero, idade, escolaridade, chefia domiciliar, condição de migrante, presença de cônjuge e município de residência.

Apesar de a maior parte dos trabalhadores da RMR ser do sexo masculino, percebe-se uma maior participação relativa de homens commuters, enquanto a presença de mulheres que realizam o deslocamento pendular é significativamente inferior à proporção de mulheres não pendulares que compõem a força de trabalho. Destaca-se também o maior percentual de trabalhadores com nível médio de escolaridade completo e superior incompleto, principalmente no grupo que realiza movimento pendular. Nesse último grupo, também se pode observar uma menor participação relativa de trabalhadores sem instrução e com nível fundamental incompleto.

A média de idade do trabalhador pendular é ligeiramente inferior àquela registrada para o trabalhador não pendular. Por outro lado, chama a atenção a forte presença de migrantes intrametropolitanos que realizaram a mudança de residência entre 2005 e 2010 no grupo de trabalhadores pendulares, ou seja, 17,8\% daqueles que efetuam a mobilidade pendular diária são migrantes recentes, contra apenas $4 \%$ no grupo de trabalhadores não pendulares. Destarte, os dados parecem fornecer pistas de que a mobilidade pendular se relaciona diretamente com a condição de migrante; aspecto que é melhor explorado na próxima seção. 
Também é possível identificar diferenças importantes na distribuição dos trabalhadores segundo o município de residência, conforme os dados da Tabela 3. Entre aqueles que realizam o trajeto intermunicipal casa-trabalho diariamente, há forte concentração de residentes nos municípios de Olinda (24\%), Paulista (16,1\%), Jaboatão dos Guararapes $(14,6 \%)$ e Camaragibe $(10,6 \%)$. Já no grupo de trabalhadores não pendulares, verifica-se maior percentual de residentes em Recife $(49,5 \%)$ e Olinda $(11,3 \%)$.

Ao observar as médias das variáveis locacionais entre os grupos de trabalhadores pendulares e não pendulares, chama a atenção no primeiro grupo: a menor média de valor de aluguel residencial ( $\mathrm{R} \$$ $235,1)$, a menor área média da APC de residência $\left(15,3 \mathrm{Km}^{2}\right)$ e a maior distância da APC de residência até a capital Recife $(18,2 \mathrm{~km})$.

Em linhas gerais, os dados da amostra sugerem a relevância da distância do município de residência à capital Recife na discriminação de trabalhadores pendulares e não pendulares, dada a forte concentração de commuters residentes em Olinda, Paulista, Jaboatão dos Guararapes e Camaragibe, que são localidades no entorno da cidade do Recife. Ademais, a menor média relativa do valor de aluguel residencial para os commuters pode ser compreendida como um indicativo do que a literatura sugere em relação aos elevados custos de habitação atuarem como uma força de repulsão em áreas centrais (MUTH, 1969; MILLS, 1972; BRUECKNER, 1987). Assim, os trabalhadores que realizam o trajeto intermunicipal casa-trabalho diariamente podem, por um lado, assumir os custos do movimento pendular, mas, por outro lado, incorrem em custos habitacionais relativamente inferiores.

\section{Resultados empíricos}

\subsection{Determinantes das escolhas de residência e de local de trabalho}

A estratégia adotada neste trabalho para a seleção de especificação do modelo empírico envolveu uma série de testes de hipóteses e de estimações prévias. A Tabela A.3 do apêndice registra os resultados dos testes de Wald e de RV para combinações de alternativas (alternativas indistinguíveis). Em todos os casos, a hipótese nula de que os 
coeficientes associados a cada par de alternativas são idênticos não pode ser aceita a $1 \%$ de significância. Esses achados são reforçados pelos testes de especificação de Hausman apresentados na Tabela A.4 do apêndice. Apesar de na primeira comparação a matriz de covariância não ter sido definida positiva, a segunda comparação entre modelos alternativos sugere a não aceitação do modelo de escolhas simultâneas, reforçando a conjectura de que as escolhas de mobilidade pendular podem ser afetadas por um processo de autosseleção prévia dos trabalhadores na condição de migrante. ${ }^{17}$

Quanto ao modelo de efeito-tratamento (1)-(2), várias especificações foram analisadas. A Tabela A.5 do apêndice registra os valores da estatística BIC a partir de estimações do modelo sob diferentes especificações em covariadas, imposição de restrição de exclusão e cópulas. Os resultados sugerem que o modelo probit bivariado baseado na cópula Frank (simétrica e densa em probabilidades nas caudas), com covariadas locacionais e restrição gerada por exclusão (inclusão da variável taxa de imigrantes recentes apenas na equação de determinação de migração - Equação (2)) é aquele que apresenta menor valor BIC. Ademais, é possível observar que a introdução de variáveis locacionais favorece a seleção da função cópula Frank (ver troca de posição nas colunas 2 e 3) e a imposição de restrição de exclusão reduz o valor BIC dada a cópula Frank (ver colunas 3 e 4).

Os resultados apresentados na Tabela 4 são baseados na seleção de especificação do modelo empírico (1)-(2). A referida Tabela mostra resultados de coeficientes obtidos em três regressões: (i) a estimação da Equação (1) de determinação de escolha da cidade de trabalho por um probit univariado - coluna 1; (ii) a estimação da Equação (2) de determinação da escolha de cidade de residência por um probit univariado - coluna 3 e (iii) a estimação conjunta das Equações (1) e (2) do modelo de efeito-tratamento - probit bivariado recursivo baseado na cópula Frank - ver colunas 2 e 4.

${ }_{17}$ Embora não reportados no texto, os resultados das estimações do modelo (5) podem ser prontamente fornecidos mediante requisição. 
Tabela 4 - Regressões: Escolhas de residência e de local de trabalho - RMR

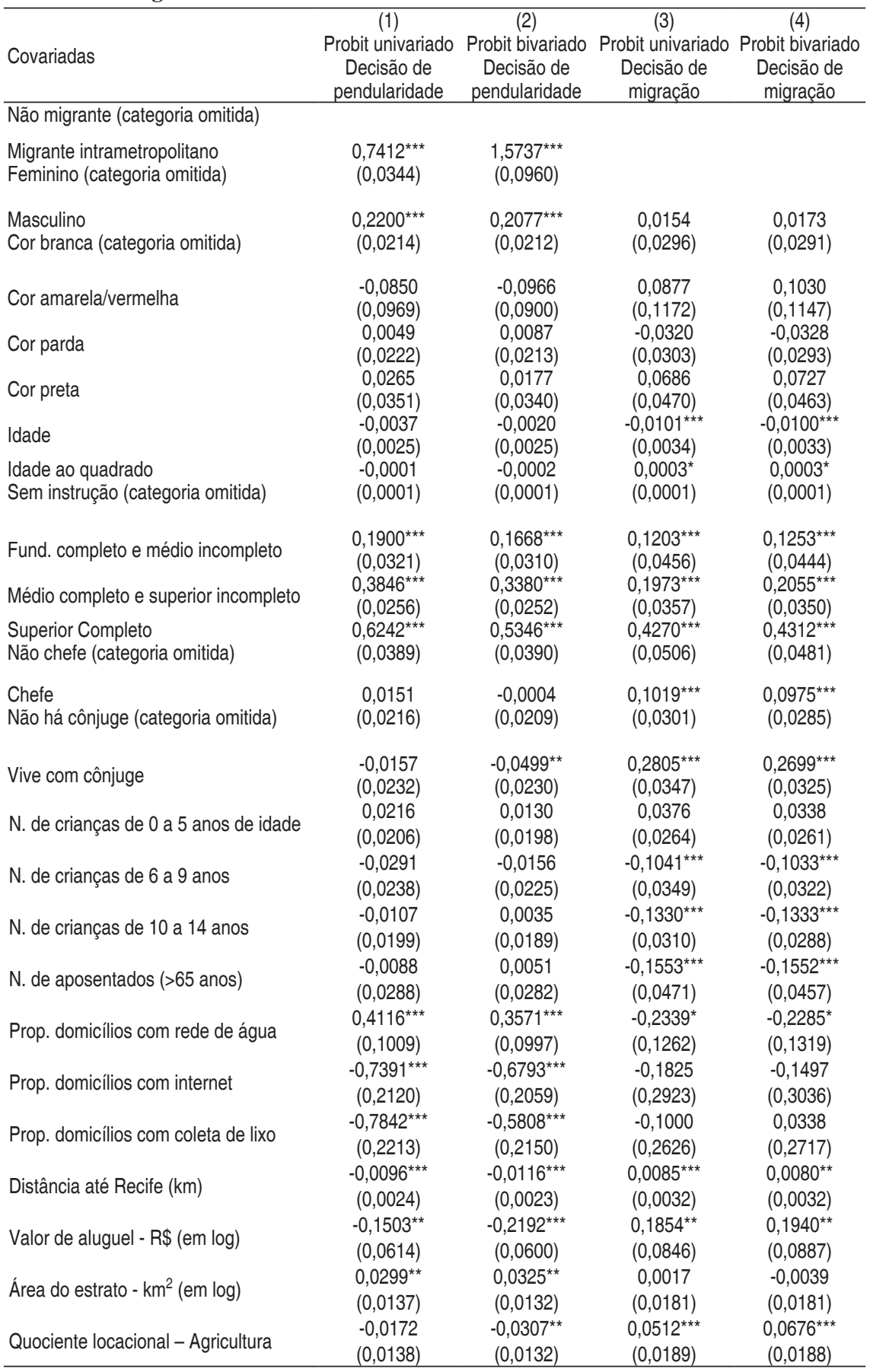


Tabela 4 - Regressões: Escolhas de residência e de local de trabalho - RMR (Continuação da página anterior)

\begin{tabular}{|c|c|c|c|c|}
\hline Covariadas & $\begin{array}{c}\text { (1) } \\
\text { Probit univariado } \\
\text { Decisão de } \\
\text { pendularidade } \\
\end{array}$ & $\begin{array}{c}\text { (2) } \\
\text { Probit bivariado } \\
\text { Decisão de } \\
\text { pendularidade }\end{array}$ & $\begin{array}{c}(3) \\
\text { Probit univariado } \\
\text { Decisão de } \\
\text { migração } \\
\end{array}$ & $\begin{array}{c}4) \\
\text { Probit bivariado } \\
\text { Decisão de } \\
\text { migração } \\
\end{array}$ \\
\hline Quociente locacional - Indústria & $\begin{array}{l}-0,0885 \\
(0,1147)\end{array}$ & $\begin{array}{l}-0,1327 \\
(0,1089)\end{array}$ & $\begin{array}{l}0,3718^{\star *} \\
(0,1552)\end{array}$ & $\begin{array}{c}0,4452^{* \star \star} \\
(0,1515)\end{array}$ \\
\hline Quociente locacional - Serviços & $\begin{array}{l}-0,1014 \\
(0,3253)\end{array}$ & $\begin{array}{l}-0,5717^{*} \\
(0,3142)\end{array}$ & $\begin{array}{c}1,8413^{* * *} \\
(0,4319)\end{array}$ & $\begin{array}{r}2,0866^{* * *} \\
(0,4330)\end{array}$ \\
\hline Quociente locacional - Social & $\begin{array}{l}0,1792^{* *} \\
(0,0901)\end{array}$ & $\begin{array}{c}0,0514 \\
(0,0877)\end{array}$ & $\begin{array}{c}0,4557^{\star \star \star} \\
(0,1276)\end{array}$ & $\begin{array}{c}0,5026^{\star \star \star} \\
(0,1243)\end{array}$ \\
\hline Quociente locacional - Adm. Pública & $\begin{array}{l}0,0441 \\
(0,0571)\end{array}$ & $\begin{array}{c}0,0584 \\
(0,0544)\end{array}$ & $\begin{array}{l}-0,0505 \\
(0,0714)\end{array}$ & $\begin{array}{l}-0,0101 \\
(0,0722)\end{array}$ \\
\hline $\begin{array}{l}\text { Prop. de imigrantes recentes } \\
\text { Recife (categoria omitida) }\end{array}$ & & & $\begin{array}{c}2,8126^{* * *} \\
(0,3139)\end{array}$ & $\begin{array}{c}2,8410^{* * *} \\
(0,2944)\end{array}$ \\
\hline Abreu e Lima & $\begin{array}{l}1,7197^{\star * *} \\
(0,0825)\end{array}$ & $\begin{array}{l}1,4564^{\star \star *} \\
(0,0840)\end{array}$ & $\begin{array}{c}0,6217^{* * *} \\
(0,1342)\end{array}$ & $\begin{array}{c}0,6291^{* * *} \\
(0,1360)\end{array}$ \\
\hline Araçoiaba & $\begin{array}{l}1,8140^{* * *} \\
(0,1538)\end{array}$ & $\begin{array}{l}1,7864^{* * *} \\
(0,1451)\end{array}$ & $\begin{array}{l}-0,1759 \\
(0,2581)\end{array}$ & $\begin{array}{l}-0,1740 \\
(0,2600)\end{array}$ \\
\hline Cabo de Santo Agostinho & $\begin{array}{l}1,1886^{* * *} \\
(0,0927)\end{array}$ & $\begin{array}{l}1,0568^{* * *} \\
(0,0889)\end{array}$ & $\begin{array}{c}0,4232^{* * *} \\
(0,1281)\end{array}$ & $\begin{array}{l}0,4591^{* * *} \\
(0,1281)\end{array}$ \\
\hline Camaragibe & $\begin{array}{l}1,7324^{* \star *} \\
(0,0512)\end{array}$ & $\begin{array}{c}1,6237^{\star \star \star} \\
(0,0510)\end{array}$ & $\begin{array}{c}0,2346^{* * *} \\
(0,0872)\end{array}$ & $\begin{array}{c}0,2460^{* * *} \\
(0,0891)\end{array}$ \\
\hline Igarassu & $\begin{array}{c}1,2273^{\star \star \star} \\
(0,0959)\end{array}$ & $\begin{array}{l}1,0952^{* * \star} \\
(0,0915)\end{array}$ & $\begin{array}{c}0,5535^{\star \star *} \\
(0,1303)\end{array}$ & $\begin{array}{c}0,5761^{\star \star *} \\
(0,1298)\end{array}$ \\
\hline Iрojuca & $\begin{array}{l}0,0355 \\
(0,1900)\end{array}$ & $\begin{array}{l}0,0062 \\
(0,1775)\end{array}$ & $\begin{array}{c}0,2982 \\
(0,1977)\end{array}$ & $\begin{array}{l}0,3551^{*} \\
(0,1984)\end{array}$ \\
\hline Itamaracá & $\begin{array}{l}0,6593^{* * *} \\
(0,1615)\end{array}$ & $\begin{array}{l}0,5055^{* \star *} \\
(0,1537)\end{array}$ & $\begin{array}{l}1,2917^{* * *} \\
(0,1904)\end{array}$ & $\begin{array}{c}1,3123^{* * *} \\
(0,1929)\end{array}$ \\
\hline Itapissuma & $\begin{array}{l}1,3423^{\star \star *} \\
(0,1511)\end{array}$ & $\begin{array}{l}1,2028^{* * *} \\
(0,1444)\end{array}$ & $\begin{array}{c}0,7062^{* * *} \\
(0,2074)\end{array}$ & $\begin{array}{c}0,7024^{* * *} \\
(0,2109)\end{array}$ \\
\hline Jaboatão dos Guararapes & $\begin{array}{c}1,4423^{* \star *} \\
(0,0502)\end{array}$ & $\begin{array}{l}1,3085^{* * *} \\
(0,0495)\end{array}$ & $\begin{array}{c}0,4125^{* * *} \\
(0,0877)\end{array}$ & $\begin{array}{c}0,4302^{* * *} \\
(0,0872)\end{array}$ \\
\hline Moreno & $\begin{array}{c}1,5233^{* \star *} \\
(0,0932)\end{array}$ & $\begin{array}{c}1,3914^{* * *} \\
(0,0910)\end{array}$ & $\begin{array}{c}0,7017^{* * *} \\
(0,1312)\end{array}$ & $\begin{array}{c}0,7009^{* * *} \\
(0,1329)\end{array}$ \\
\hline Olinda & $\begin{array}{c}1,4470^{\star \star *} \\
(0,0361)\end{array}$ & $\begin{array}{c}1,3430^{\star \star *} \\
(0,0371)\end{array}$ & $\begin{array}{c}0,3178^{\star \star *} \\
(0,0731)\end{array}$ & $\begin{array}{l}(0,3331) \\
(0,0707)\end{array}$ \\
\hline Paulista & $\begin{array}{c}1,5024^{\star \star *} \\
(0,0528)\end{array}$ & $\begin{array}{c}1,2558^{\star \star \star} \\
(0,0584)\end{array}$ & $\begin{array}{c}0,6866^{\star * \star} \\
(0,1017)\end{array}$ & $\begin{array}{c}0,7074^{\star * *} \\
(0,1000)\end{array}$ \\
\hline São Lourenço da Mata & $\begin{array}{c}1,6699^{* * *} \\
(0,0805)\end{array}$ & $\begin{array}{c}1,4930^{* * *} \\
(0,0776)\end{array}$ & $\begin{array}{c}0,7041^{* * *} \\
(0,1088)\end{array}$ & $\begin{array}{c}0,6981^{* * *} \\
(0,1095)\end{array}$ \\
\hline Intercepto & $\begin{array}{l}-0,0033 \\
(0,6497)\end{array}$ & $\begin{array}{c}0,8884 \\
(0,6200)\end{array}$ & $\begin{array}{c}-6,1462^{* * *} \\
(0,8566)\end{array}$ & $\begin{array}{c}-6,7748^{* * *} \\
(0,8464)\end{array}$ \\
\hline
\end{tabular}

Coeficiente de dependência (Intervalo de confiança 95\%): $\theta=-3,89(-5,34,-2,67)$

Observações: 22.541

Teste de Wald: p-valor: 0,000

Fonte: Elaboração própria a partir dos microdados do Censo Demográfico de 2010.

Nota: $\mathrm{O}$ modelo bivariado é do tipo cópula Frank. Erros-padrão robustos à heterocedasticidade.

***Estatisticamente significante a $1 \% .{ }^{* *}$ Estatisticamente significante a $5 \% .{ }^{*}$ Estatisticamente significante a $10 \%$. 
A principal evidência reportada diz respeito à correlação direta entre escolha prévia de residência e escolha de local de trabalho. É possível observar que o coeficiente associado à dummy de condição de migrante intrametropolitano nas regressões das colunas 1 e 2 é positivo e estatisticamente significativo a $1 \%$, sugerindo que trabalhadores com recente histórico de mudança de residência (migrantes) são mais propensos à mobilidade pendular que os não migrantes (categoria omitida). Esse resultado corrobora alguns estudos internacionais que já haviam, de certa forma, indicado uma relação complementar entre migração e mobilidade pendular (RENKOW; HOOVER, 2000; LUNDHOLM, 2010; AXISA; SCOTT; NEWBOLD, 2012).

Todavia, a regressão da coluna 1 trata a decisão de migração (escolha de local de residência) como um processo aleatório e não relacionado a habilidades inatas que afetam a decisão de mobilidade pendular, enquanto a regressão apresentada na coluna 2 considera a correção do coeficiente para viés de seleção amostral envolvido na condição de migrante. Conforme os resultados, quando não se controla a autosseleção dos migrantes em atributos observados e não observados, o coeficiente da variável binária de migração é subestimado $(0,7412$, contra 1,5737 no modelo bivariado), fato que caracteriza um considerável viés de seleção na regressão da coluna 1 . Tal achado é relevante uma vez que a maior parte dos estudos realizados no campo de análise não se atenta para o problema de que trabalhadores pendulares com habilidades inatas podem se autosselecionar enquanto migrantes, isto é, deles não serem distribuídos de forma aleatória na amostra.

O teste de Wald indica que a hipótese nula de independência estatística das equações de resultado potencial (decisão de mobilidade pendular) e de seleção (decisão de migrar) pode ser rejeitada a $1 \%$, isto é, o modelo bivariado (com cópula Frank) é estatisticamente preferível ao modelo univariado. Ademais, o coeficiente de dependência das Equações (1) e (2) registra valor $\theta=3,89$ (cuja estatística $\theta$ de Kendall correspondente é 0,38), dado que sugere uma dependência negativa entre as distribuições marginais de probabilidade.

No tocante à correlação da decisão de local trabalho com o gênero do trabalhador, nota-se que, em relação às mulheres (categoria de referência), trabalhadores homens são mais propensos ao movimento pendular. 
Neste sentido, McQuaid e Chen (2012) já haviam ressaltado a existência de uma probabilidade de realização de deslocamentos pendulares para indivíduos do sexo masculino, em análise da força de trabalho do Reino Unido. Por outro lado, Miranda e Domingues (2010) também perceberam que as mulheres costumam trabalhar mais próximas de suas residências, na sua análise da Região Metropolitana de Belo Horizonte.

Os resultados também revelam que a decisão de migração intrametropolitana está inversamente associada à idade do trabalhador. Por outro lado, é possível observar que as escolhas de migração e de mobilidade pendular estão diretamente relacionadas ao nível de instrução, conforme prediz a abordagem do capital humano. Ou seja, o investimento em educação pode aumentar o retorno salarial sobre as horas trabalhadas e oferecer mais oportunidades de emprego, enquanto pessoas mais jovens tendem a assumir riscos envolvidos na mobilidade (OMMEREN; RIETVELD; NIJKAMP, 1999; ROUWENDAL; RIETVELD, 1994; HUBER, 2014).

As condições presentes nos domicílios também apresentam correlações com as escolhas de cidade de trabalho e cidade de residência. No caso de um trabalhador responsável pelo domicílio, percebe-se que o mesmo tem maior chance de migrar em relação a um trabalhador não chefe de domicílio. No entanto, a convivência com cônjuge no domicílio favorece a mudança de residência no meio metropolitano e desfavorece a mobilidade pendular. Já a presença de idosos aposentados no domicílio desestimula a migração.

A infraestrutura urbana também parece discriminar as decisões de mobilidade pendular e residencial. Enquanto pessoas que residem em setores censitários (APC) com elevada proporção de domicílios com acesso à água encanada registram maior chance de trabalhar em outro município e menor propensão a mudar de residência, aqueles residentes em APC com maior acesso à coleta de lixo ou acesso à internet são menos propensas a mudança de local de trabalho.

Outros achados interessantes foram capturados pelas variáveis proxies de mercado residencial e acessibilidade. Por exemplo, os coeficientes associados à variável "valor de aluguel residencial" sugerem que pessoas residentes em setores censitários com maior custo habitacional são mais propensas a mudar de residência para outro municí- 
pio e registram menor probabilidade de efetuar mobilidade pendular para outra cidade. Quanto maior a distância rodoviária da APC de residência para a capital Recife, menor a chance de o indivíduo realizar o movimento pendular e maior a probabilidade de ser migrante intrametropolitano. Ademais, residentes em setores de maior área são mais propensos a trabalhar em outro município. Tais resultados estão de acordo com as relações teóricas referentes aos movimentos casa-trabalho dos modelos de economia urbana (MUTH, 1969; MILLS, 1972; BRUECKNER, 1987).

As variáveis referentes aos "quocientes locacionais" procuram capturar efeitos da distribuição regional de áreas especializadas em diferentes atividades econômicas (oportunidades de emprego). Nesse sentido, os resultados da Tabela 4 indicam que um aumento na participação de empregos em atividades agrícolas e, sobretudo, serviços da APC, tendem a reduzir a probabilidade de o trabalhador efetuar a mobilidade pendular e aumenta a chance de mudar de residência. Tal resultado é bastante razoável, uma vez que, em geral, localidades com maiores coeficientes de especialização nos setores de serviços são centros urbanos e, muitas vezes, com maior densidade de traba1ho. Logo, os residentes possuem menos incentivos para realização dos deslocamentos pendulares (LUNDHOLM, 2010). Por outro lado, um aumento da participação de empregos no setor social (inclusive empregos nas áreas de educação e de saúde) parece favorecer a probabilidade tanto de realizar a mobilidade pendular, quanto de ser migrante.

Em relação às dummies municipais para localização residencial, notase que o deslocamento pendular é relativamente mais favorecido em todos os demais municípios, comparativamente a Recife. Por outro lado, há maior probabilidade de ser migrante para aqueles que residem em qualquer município que não Recife.

A variável "proporção de migrantes recentes (com 6 a 9 anos de residência no município recenseado)" foi utilizada como restrição de exclusão para auxiliar na identificação estrutural do modelo (1)-(2). Ou seja, essa variável procura discriminar efeitos associados à presença de redes de migrantes ou redes sociais, sob a hipótese de que setores censitários (APC) com maior participação de imigrantes também podem apresentar maior fluxo (sinalização) de informações sobre oportunidades de emprego e condições de vida nessas locali- 
dades, assim como o fornecimento de suporte financeiro e logístico para a chegada de novos trabalhadores migrantes no período posterior. Os resultados em análise sugerem que a decisão de migrar na metrópole do Recife está diretamente associada com recentes taxas de imigração, ou seja, em setores censitários com maior participação de imigrantes com 6 a 9 anos de residência é maior a chance de se encontrar um imigrante com até 5 anos de residência no município recenseado.

\subsection{Efeito da condição de migrante sobre a mobilidade pendular}

A principal questão de investigação deste estudo é identificar qual é o efeito da mudança prévia de residência sobre a escolha de trabalhar em outro município na RMR. Ou seja, deve-se estimar qual é o efeito da condição de migrante recente sobre a mobilidade pendular. Para tanto, após o controle de características pessoais, locacionais e autosseleção de migrantes em variáveis não observadas - habilidades inatas -, foi calculada a diferença de probabilidade de mobilidade pendular provocada por uma mudança da condição individual de não migrante - indivíduo não tratado - para a condição de migrante indivíduo tratado - (ATE), conforme a Equação (7).

Além de calculado para a amostra total, o ATE também foi computado por subamostras por gênero, faixas etárias e faixas de instrução, na tentativa de averiguar possíveis efeitos heterogêneos. As estimativas ATE são apresentadas na Tabela 5. Elas consideram os coeficientes estimados para o modelo probit bivariado recursivo mais bem ajustado (cópula Frank) e outros obtidos por modelos mais simples, que ignoram: (i) efeitos de covariadas observadas (probit univariado sem controles - apenas dummy de migração como covariada), (ii) efeitos de variáveis não observadas (probit univariado com controles) e (iii) distribuições conjuntas não normais (probit bivariado recursivo com cópula Gaussiana). Os intervalos de confiança a 95\% se acham entre parênteses. 
Tabela 5 - Estimativas de efeitos da migração (escolha de residência) sobre a mobilidade pendular (escolha de local de trabalho segundo gênero, faixa etária e escolaridade) - ATE

\begin{tabular}{lcccc}
\hline & $\begin{array}{c}(1) \\
\text { Probit univariado } \\
\text { sem controles }\end{array}$ & $\begin{array}{c}(2) \\
\text { Probit univariado controles } \\
\text { com }\end{array}$ & $\begin{array}{c}(3) \\
\text { Probit bivariado } \\
\text { Cópula-Gaussiana }\end{array}$ & $\begin{array}{c}(4) \\
\text { Probit bivariado } \\
\text { Cópula-Frank }\end{array}$ \\
\hline Gênero & & & & \\
Masculino & 38,48 & 22,46 & 44,16 & 47,73 \\
& $(37,63 ; 39,33)$ & $(20,61 ; 24,36)$ & $(38,03 ; 50,55)$ & $(44,18 ; 52,35)$ \\
Feminino & 39,67 & 21,40 & 43,63 & 47,39 \\
& $(38,83 ; 40,51)$ & $(19,21 ; 23,20)$ & $(36,49 ; 49,79)$ & $(40,98 ; 51,07)$ \\
Faixa Etária & & & & \\
Idade entre 25 e 30 anos & 34,19 & 22,74 & 44,19 & 47,70 \\
& $(33,32 ; 35,06)$ & $(20,58 ; 25,27)$ & $(37,40 ; 49,77)$ & $(42,02 ; 53,01)$ \\
Idade entre 41 e 50 anos & 37,88 & 22,37 & 44,19 & 47,77 \\
Idade entre 41 e 50 anos & $(37,02 ; 38,73)$ & $(19,94 ; 25,17)$ & $(37,85 ; 50,84)$ & $(42,49 ; 53,03)$ \\
& 46,65 & 21,33 & 43,65 & 47,43 \\
Idade entre 51 e 65 anos & $(45,83 ; 47,46)$ & $(19,14 ; 23,24)$ & $(37,49 ; 50,24)$ & $(40,45 ; 51,99)$ \\
Faixa de instrução & 41,73 & 20,34 & 43,03 & 46,98 \\
Sem instrução e fund. incompleto & $(40,91 ; 42,55)$ & $(18,14 ; 22,18)$ & $(35,88 ; 50,19)$ & $(41,53 ; 52,32)$ \\
& $(36,69 ; 38,36)$ & $(19,61 ; 23,47)$ & $(37,97 ; 49,70)$ & $(43,70 ; 52,81)$ \\
Fund. comp. e médio incompleto & 37,99 & 22,34 & 44,19 & 47,80 \\
& $(37,14 ; 38,84)$ & $(20,39 ; 24,31)$ & $(38,51 ; 49,99)$ & $(42,34 ; 52,00)$ \\
Médio comp. e superior incompleto & 37,54 & 22,66 & 43,95 & 47,45 \\
Superior Completo & $(36,68 ; 38,39)$ & $(20,26 ; 24,65)$ & $(37,80 ; 49,46)$ & $(42,85 ; 53,49)$ \\
Total & 41,81 & 20,93 & 43,71 & 47,58 \\
& $(40,98 ; 42,65)$ & $(18,82 ; 22,90)$ & $(37,22 ; 49,78)$ & $(41,56 ; 52,34)$ \\
& 38,96 & 22,06 & 43,96 & 47,60 \\
\hline
\end{tabular}

Fonte: Elaboração própria a partir dos microdados do Censo Demográfico de 2010.

Nota: Intervalos de confiança a 95\% entre parênteses foram obtidos pelo método Delta.

Em linhas gerais, os achados da Tabela 5 apontam que trabalhadores com histórico recente de migração intrametropolitana são mais propensos à mobilidade pendular que os não migrantes; resultado persistente mesmo após considerar que os trabalhadores são autosselecionados na condição de migrante (ver colunas 3 e 4). Destarte, tal evidência corrobora a hipótese de que as decisões de migração e mobilidade pendular são complementares (RENKOW; HOOVER, 2000; AXISA; SCOTT; NEWBOLD, 2012).

Conforme os resultados apresentados na coluna 4, nota-se que a probabilidade de mobilidade pendular é cerca de 47,6 p.p maior para um trabalhador típico que mudou de residência entre cidades metropolitanas no quinquênio 2005-2010, comparado a um trabalhador que nasceu e sempre residiu no município onde foi recenseado. Ademais, os dados não sugerem a presença efeitos heterogêneos entre grupos de gênero, instrução e faixa etária. Quando se cotejam as estimativas 
ATE pelos referidos grupos, inclusive com o ATE total, não se percebem fortes diferenças. Ao contrário, os valores ATE são bastante próximos e há sobreposição de intervalos de confiança.

Outros aspectos importantes devem ser observados na Tabela 5. Primeiro, os valores ATE são subestimados quando não se considera o processo de autosseleção na decisão de migração (escolha residencial), aspecto comum na literatura especializada. Por exemplo, na coluna 1 , os resultados são derivados da estimação da Equação (1) por um probit univariado, tendo como única covariada uma dummy de migração, isto é, ignorando a autosseleção dos migrantes e efeitos de variáveis pessoais, domiciliares e locacionais. Nesse caso, estima-se que um migrante tem uma probabilidade 38,9 p.p maior de mobilidade pendular que um não migrante, contra 47,6 p.p no modelo mais geral (ver coluna 4). Já na coluna 2, as estimativas ATE são derivadas da estimação da Equação (1) com todas as covariadas selecionadas neste estudo, porém, ainda considerado que dummy de migração não se correlaciona do termo randômico do modelo. Assim, percebe-se que o efeito da condição de migrante ainda permanece subestimado, 221 p.p.

Em segundo lugar, quando se comparam os resultados das colunas 3 e 4, nota-se que as estimativas pontuais do ATE, no caso do pressuposto de distribuição conjunta Gaussiana (ver coluna 3), parecem ser, em geral, ligeiramente subestimadas, embora as sobreposições das estimativas por intervalos não permitam concluir que há diferenças

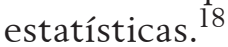

A Figura 3 registra valores ATE calculados considerando grupos de migrantes e não migrantes por distância rodoviária da APC de residência ao marco zero da cidade do Recife.

18 O fato de a cópula Frank ser simétrica e se aproximar da Gaussiana permite resultados relativamente próximos. No entanto, sua maior concentração de probabilidade nas caudas permite maior flexibilidade nas estimativas, minimizando pequenos vieses. 


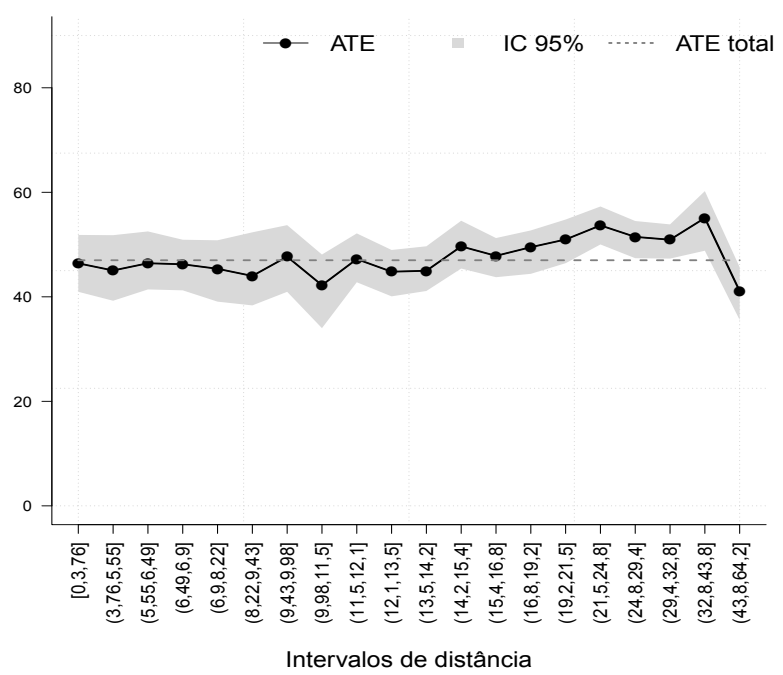

Figura 3 - Efeitos da migração (escolha de residência) sobre a mobilidade pendular (escolha de local de trabalho) segundo a distância rodoviária (Km) da APC de residência até a capital Recife

Nota: Intervalos de distância definidos por 20 quantis da distribuição amostral. Valores ATE e intervalos de confiança obtidos a partir do modelo de efeito-tratamento com cópula Frank. Intervalos de confiança a $95 \%$ obtidos pelo método Delta.

Apesar de as estimativas pontuais do ATE serem relativamente maiores para intervalos de distâncias de $21 \mathrm{Km}$ a $44 \mathrm{Km}$, os resultados não permitem inferir que há fortes diferenças de probabilidade de mobilidade pendular entre grupos de migrantes localizados mais próximos à capital e grupos que residem em APC mais distantes. Mesmo para os maiores valores ATE estimados, os intervalos de confiança se aproximam bastante da estimativa pontual do ATE total e há sobreposições com estimativas intervalares para distâncias menores.

\section{Considerações finais}

Durante as últimas décadas, os movimentos pendulares adquiriram crescente visibilidade em áreas metropolitanas. Sua dinâmica e rebatimentos são alvo de interesse para formuladores de políticas públicas direcionadas a melhoria da mobilidade urbana. Nesse contexto, o objetivo deste estudo foi investigar se há relação entre mobilidade 
pendular (escolha de local de trabalho) e migração intrametropolitana (escolha de residência) na RMR. Para tanto, usando dados recentes do Censo Demográfico de 2010, estimou-se um modelo econométrico de efeito-tratamento baseado em cópulas, no qual se incorpora um processo prévio de autosseleção de trabalhadores enquanto migrantes e não migrantes.

Os achados empíricos permitem inferir que há uma associação complementar (direta) entre as escolhas de mudança residencial e de alteração de local de trabalho na RMR, favorecendo a hipótese de que o processo de descentralização urbana afeta positivamente os movimentos pendulares. Ou seja, as estimativas deste estudo sugerem que um trabalhador com histórico recente de migração na RMR tem, em média, 47,6 p.p. a mais de probabilidade de efetuar a mobilidade pendular quando comparado a um não migrante. Essa estimativa tende a ser enviesada (subestimada) quando se considera que trabalhadores pendulares e não pendulares mudam de residência sem qualquer relação com a decisão de mobilidade pendular, seja em atributos observados ou em habilidades inatas.

Entender o processo de descentralização espacial no meio urbano, bem como os movimentos diários de jornada casa-trabalho na esfera metropolitana, é de suma importância para a elaboração de políticas públicas. Ademais, como os movimentos migratórios e a mobilidade pendular se revelam associados com demandas por moradia, transporte e demais serviços públicos, faz-se necessário o conhecimento das características e necessidades dos trabalhadores envolvidos nessa dinâmica. Neste estudo, há evidências de que o trabalhador migrante, homem e com instrução superior é mais propenso à mobilidade pendular na RMR. Por conseguinte, políticas de moradia e de transporte urbano poderiam levar em consideração essas características, seja, por exemplo, na discriminação de taxas de subsídios de tarifas de transporte, aluguel de imóveis e/ou na seleção de candidatos a programas de auxílio-moradia e financiamento imobiliário. 


\section{Referências}

ÂNTICO, C. Deslocamentos pendulares na região metropolitana de São Paulo. São Paulo em Perspectiva, Scielo, v. 19, n. 4, p. 110-120, 2005. ISSN 0102-8839. Disponível em: <http://dx.doi.org/10.1590/ S0102-88392005000400007>.

ARANHA, V. Mobilidade pendular na metrópole paulista. São Paulo em Perspectiva, Scielo, v. 19, n. 4, p. 96-109, 2005. ISSN 0102-8839. Disponível em: <http://dx.doi.org/10.1590/ S0102$88392005000400006>$.

AXISA, J. J.; SCOTT, D. M.; NEWBOLD, K. B. Factors influencing commute distance: a case study of Toronto's commuter shed. Journal of Transport Geography, v. 24, p. 123-129, 2012. Disponível em: <http://www.sciencedirect.com/science/article/pii/S0966692311001566>.

BETARELLI JUNIOR, A. A. Custo de acessibilidade entre residência e trabalho: um enfoque das características individuais, familiares e locais. 2010. Disponível em: <http://ideas.repec.org/p/ cdp/texdis/td407.html $>$.

BRECHMANN, E. C.; SCHEPSMEIER, U. Modeling Dependence with C- and D-Vine Copulas: The R Package CDVine. Journal of Statistical Software, v. 52, n. 3, p. 1-27, 2013. ISSN 1548-7660. Disponível em: <http://www.jstatsoft.org/v52/i03>.

BRUECKNER, J. K. Chapter 20 The structure of urban equilibria: A unified treatment of the muth-mills model. In: MILLS, E. S. (Ed.). Urban Economics. Elsevier, 1987, (Handbook of Regional and Urban Economics, v. 2). p. 821-845. Disponível em: <http://www.sciencedirect.com/science/ article/pii/S1574008087800068>.

CAMERON, A.; TRIVEDI, P. Microeconometrics: Methods and Applications. Cambridge University Press, 2005. ISBN 9780521848053. Disponível em: <https://books.google.ca/books?id= Zf0gCwxC9ocC>.

CHAMPION, T.; COOMBES, M.; BROWN, D. L. Migration and Longer-Distance Commuting in Rural England. Regional Studies, v. 43, n. 10, p. 1245-1259, 2009. Disponível em: <http://rsa. tandfonline.com/doi/abs/10.1080/00343400802070902>.

CHISWICK, B. R. Are Immigrants Favorably Self-Selected? The American Economic Review, American Economic Association, v. 89, n. 2, p. 181-185, 1999. ISSN 00028282. Disponível em: <http:// www.jstor.org/stable/117103>.

DOS SANTOS JÚNIOR, E. d. R.; MENEZES-FILHO, N.; FERREIRA, P. C. Migração, seleção e diferenças regionais de renda no Brasil. Pesquisa e Planejamento Econômico, v. 35, n. 3, p. 299-331, 2005. Disponível em: <http://ppe.ipea.gov.br/index.php/ppe/article/viewFile/47/25>.

EVERS, G. H. M.; VAN DER VEEN, A. A simultaneous non-linear model for labour migration and commuting. Regional Studies, v. 19, n. 3, p. 217-229, 1985.

FINDLAY, A. M. et al. Mobility as a driver of change in rural Britain: an analysis of the links between migration, commuting and travel to shop patterns. International Journal of Population Geography, John Wiley \& Sons, Ltd., v. 7, n. 1, p. 1-15, 2001. ISSN 1099-1220. Disponível em: <http:// dx.doi.org/10.1002/ijpg.201>.

FREEDMAN, O.; KERN, C. R. A model of workplace and residence choice in two-worker households. Regional Science and Urban Economics, v. 27, n. 3, p. 241-260, 1997. ISSN 01660462.

FREGUGLIA, R. d. S. Efeitos da migração sobre os salários no Brasil. 1-126 p. Tese (Doutorado) USP, 2007.

GLAESER, E. L. Are Cities Dying? Journal of Economic Perspectives, v. 12, n. 2, p. 139-160, 1998. Disponível em: <http://www.aeaweb.org/articles.php?doi=10.1257/jep.12.2.139>.

HECKMAN, J.; NAVARRO-LOZANO, S. Using Matching, Instrumental Variables, and Control Functions to Estimate Economic Choice Models. The Review of Economics and Statistics, The 
MIT Press, v. 86, n. 1, p. 30-57, 2004. ISSN 00346535. Disponível em: <http://www.jstor.org/ stable/3211658>.

HECKMAN, J. J. Sample Selection Bias as a Specification Error. Econometrica, v. 47, n. 1, p. 153-161, 1979.

HUBER, P. Are Commuters in the EU Better Educated than Non-commuters but Worse than Migrants? Urban Studies, v. 51, n. 3, p. 509-525, 2014.

JARDIM, A. D. P. A investigação das migrações internas, a partir dos Censos Demográficos brasileiros de 1970 a 2010. In: OLIVEIRA, L. A. P. de; OLIVEIRA, A. T. R. de (Ed.). Reflexões sobre os Deslocamentos Populacionais no Brasil. 1. ed. Rio de Janeiro: Instituto Brasileiro de Geografia e Estatística - IBGE, 2011. p. 1-103. Disponível em: <http://www.ibge.gov.br/home/ estatistica/ populacao/reflexoes $\backslash$ deslocamentos/deslocamentos.pdf $>$.

JARDIM, A. d. P.; ERVATTI, L. Migração pendular intrametropolitana no Rio de Janeiro: reflexões sobre o seu estudo, a partir dos Censos Demográficos de 1980 e 2000. 2007.

LONG, J. Regression Models for Categorical and Limited Dependent Variables. SAGE Publications, 1997. ISBN 9780803973749. Disponível em: <https://books.google.ca/books?id= CHvSWpAyhdIC >.

LÖSCH, A. The economics of location. 2. ed. New Haven: Yale University Press, 1954. v. 8. 1-520 p. ISSN 1467-6435. Disponível em: <http://www.economia.unam.mx/cedrus/descargas/ economicsoflocat001s.pdf $>$.

LUNDHOLM, E. Interregional migration propensity and labour market size, Sweden 1970-2001. Regional Studies, v. 44, n. 4, p. 455-464, 2010. Disponível em: <http://nbn-resolving.de/urn: nbn:de:0168-ssoar-246408>.

MAGALHÃES, D. J. A. V.; RIOS NETO, E. L. G. Uma abordagem multinível para análise da mobilidade residencial na Região Metropolitana de Belo Horizonte. Rebep, v. 21, n. 1, p. 137-156, 2004. Disponível em: <http://www.abep.nepo.unicamp.br/docs/rev\_inf/vol21 $\_$n1 _2004/

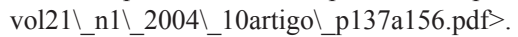

MARRA, G.; RADICE, R. Estimation of a semiparametric recursive bivariate probit model in the presence of endogeneity. Canadian Journal of Statistics, John Wiley \& Sons, Inc., v. 39, n. 2, p. 259-279, 2011. ISSN 1708-945X. Disponível em: <http://dx.doi.org/10.1002/cjs.10100>.

MCQUAID, R. W.; CHEN, T. Commuting times - The role of gender, children and part-time work. Research in Transportation Economics, v. 34, n. 1, p. 66-73, 2012. ISSN 0739-8859. Disponível em: <http://www.sciencedirect.com/science/article/pii/S0739885911000655>.

MILLS, E. S. Studies in the Structure of the Urban Economy. Baltimore: Johns Hopkins Press, 1972. $172 \mathrm{p}$.

MIRANDA, R. A. de; DOMINGUES, E. P. Commuting to work and residential choices in the metropolitan area of Belo Horizonte, Brazil. Urban Public Economics Review, v. 12, p. 41-71, 2010.

MOURA, R.; BRANCO, M. L. G. C.; FIRKOWSKI, O. C. D. F. Movimento pendular e perspectivas de pesquisas em aglomerados urbanos. São Paulo em Perspectiva, SciELO,

v. 19, n. 4, p. 121-133, 2005. ISSN 0102-8839. Disponível em: <http://dx.doi.org/10.1590/ S0102$88392005000400007>$.

MOURA, R.; DELGADO, P.; COSTA, M. A. Movimento Pendular e Políticas Públicas: Algumas possibilidades inspiradas numa tipologia dos municípios brasileiros. In: BOUERI, R.; COSTA, M. A. (Ed.). Brasil em desenvolvimento 2013 : estado, planejamento e políticas públicas. Brasília:

Instituto de Pesquisa Econômica Aplicada (IPEA), 2013. cap. 22, p. 665-696. Disponível em: <http:// www.ipea.gov.br/agencia/images/stories/PDFs/livros/livros/livro\_brasil $\backslash$ _desenvolvimento2013 \vo103.pdf>.

MUTH, R. F. Cities and housing : the spatial pattern of urban residential land use. Chicago: University of Chicago Press, 1969. 355 p. 
NELSEN, R. B. An Introduction to Copulas (Springer Series in Statistics). Secaucus, NJ, USA: SpringerVerlag New York, Inc., 2006. ISBN 0387286594.

OMMEREN, J. van; RIETVELD, P.; NIJKAMP, P. Job Moving, Residential Moving, and Commuting: A Search Perspective. Journal of Urban Economics, v. 46, n. 2, p. 230-253, 1999. ISSN 00941190. Disponível em: <http://www.sciencedirect.com/science/article/pii/ S0094119098921209>.

PAPANIKOLAOU, G. Spatial and Individual Influence on Commuting Behaviour in Germany. In: 46th Congress of the European Regional Science Association (ERSA). Volos (Grécia): [s.n.], 2006. Disponível em: <http://www-sre.wu-wien.ac.at/ersa/ersaconfs/ersa06/papers/468.pdf >.

PIRACHA, M.; VADEAN, F. Return Migration and Occupational Choice: Evidence from Albania. World Development, v. 38, n. 8, p. 1141-1155, 2010. ISSN 0305-750X. Disponível em: <http:// www.sciencedirect.com/science/article/pii/S0305750X10000045>.

RADICE, R.; MARRA, G.; WOJTYS, M. Copula Regression Spline Models for Binary Outcomes With Application in Health Care Utilization. 2013. Disponível em: < http://www.ucl.ac.uk/statistics/ research/pdfs/rr321.pdf $>$.

RAO, C. R.; TOUTENBURG, H. Linear models. 2. ed. New York: Springer-Verlag, 1999. 1-443 p.

RENKOW, M.; HOOVER, D. Commuting, Migration, and Rural-Urban Population Dynamics. Journal of Regional Science, v. 40, n. 2, p. 261-287, 2000. Disponível em: <http://ideas.repec.org/a/bla/ jregsc/v40y2000i2p261-287.html>.

ROUWENDAL, J.; RIETVELD, P. Changes in Commuting Distances of Dutch Households. Urban Studies, v. 31, n. 9, p. 1545-1557, nov. 1994. Disponível em: <http://usj.sagepub.com/content/31/9/1545.abstract>.

SANDOW, E.; WESTIN, K. The persevering commuter - Duration of long-distance commuting.

Transportation Research Part A: Policy and Practice, v. 44, n. 6, p. 433-445, 2010. ISSN 0965-8564. Disponível em: <http://www.sciencedirect.com/science/article/pii/S096585641000056X>.

SOARES, M. R. M. Migração intrametropolitana e movimentos pendulares na Região Metropolitana de Belo Horizonte: o caso do município de Contagem -1991/2000. 1-141 p. Tese (Doutorado) - UFMG, 2006.

TOOMET, O.; HENNINGSEN, A. Sample Selection Models in R: PackagesampleSelection. Journal of Statistical Software, 2008. Disponível em: <http://cran.fhcrc.org/web/packages/ sampleSelection/ vignettes/selection.pdf $>$.

TROSHCHENKOV, S. Commuting to work - self-selection on earnings and unobserved heterogeneity. 1-32 p. Tese (Doutorado) — UmeåUniversitet, 2012. Disponível em: <http://www.diva-portal. org/smash/get/diva2:615155/FULLTEXT01.pdf>.

VAN OMMEREN, J.; DARGAY, J. The Optimal Choice of Commuting Speed: Consequences for Commuting Time, Distance and Costs. Journal of Transport Economics and Policy, v. 40, p. 279-296, 2006. Disponível em: <http://ideas.repec.org/p/dgr/uvatin/20040092.html>.

VON THÜNEN, T. H. The isolated state. New York: Pergamon Press, 1966.

WINKELMANN, R. Copula Bivariate Probit Models: With An Application To Medical Expenditures. Health Economics, v. 21, n. 12, p. 1444-1455, 2012. Disponível em: <http://ideas.repec.org/a/ wly/hlthec/v21y2012i12p1444-1455.html>.

ZAX, J. S. When is a move a migration? Regional Sciences and Urban Economics, v. 24, n. 3, p. 341-360, 1994. ISSN 01660462. 


\section{Apêndice}

Tabela Al - Distribuição e participação de trabalhadores pendulares segundo a Região Metropolitana de residência - $12 \mathrm{RMs}$ mais populosas do Brasil - 2010

\begin{tabular}{lcccccc}
\hline & $(\mathrm{a})$ & $(\mathrm{b})$ & $(\mathrm{c})$ & $(\mathrm{d})$ & $(\mathrm{e})=(\mathrm{b}) /(\mathrm{d})$ & $(\mathrm{f})=(\mathrm{d}) /(\mathrm{a})$ \\
\hline RM de & $\begin{array}{c}\text { População } \\
\text { residente }\end{array}$ & $\begin{array}{c}\text { Pessoas que } \\
\text { trabalham fora } \\
\text { do município } \\
\text { onde residem } \\
\text { commuters }\end{array}$ & $\begin{array}{c}\text { Pessoas que } \\
\text { trabalham } \\
\text { no município } \\
\text { onde residem } \\
\text { (não commuters) }\end{array}$ & $\begin{array}{c}\text { Pessoas } \\
\text { ocupadas }\end{array}$ & $\begin{array}{c}\text { Participação de } \\
\text { commuters \% }\end{array}$ & $\begin{array}{c}\text { Participação } \\
\text { de ocupados \% }\end{array}$ \\
São Paulo & 19.683 .975 & 1.541 .483 & 5.333 .381 & 6.874 .864 & 22,4 & 34,9 \\
Rio de Janeiro & 11.835 .708 & 876.123 & 2.978 .399 & 3.854 .521 & 22,7 & 32,6 \\
Belo Horizonte & 5.414 .701 & 499.620 & 1.533 .943 & 2.033 .563 & 24,6 & 37,6 \\
Porto Alegre & 3.958 .985 & 415.319 & 1.087 .544 & 1.502 .864 & 27,6 & 38,0 \\
Recife & 3.690 .547 & 349.568 & 779.774 & 1.129 .342 & 31,0 & 30,6 \\
Fortaleza & 3.615 .767 & 119.373 & 998.341 & 1.117 .714 & 10,7 & 30,9 \\
Salvador & 3.573 .973 & 115.272 & 1.059 .541 & 1.174 .813 & 9,8 & 32,9 \\
Curitiba & 3.174 .201 & 294.238 & 906.816 & 1.201 .054 & 24,5 & 37,8 \\
Campinas & 2.797 .137 & 251.258 & 803.593 & 1.054 .851 & 23,8 & 37,7 \\
Goiânia & 2.173 .141 & 168.077 & 654.355 & 822.432 & 20,4 & 37,8 \\
Manaus & 2.106 .322 & 3.613 & 599.831 & 603.444 & 0,6 & 28,6 \\
Belém & 2.101 .883 & 104.154 & 534.649 & 638.803 & 16,3 & 30,4 \\
\hline Brasil & 190.755 .799 & 8.105 .950 & 51.998 .788 & 60.104 .738 & 13,5 & 31,5 \\
\hline
\end{tabular}

Fonte: Elaboração própria a partir dos microdados do Censo Demográfico de 2010.

Notas: i. Para classificação dentro do grupo das regiões metropolitanas mais importantes, utilizou-se o critério de tamanho populacional, bem como ano de criação da região metropolitana. ii. Apenas trabalhadores ocupados e que realizam trajeto diário casa-trabalho.

Tabela A2 - Características de funções cópulas selecionadas

\begin{tabular}{lcc}
\hline Cópula & Forma funcional $C(u, v ; \theta)$ & Parâmetro de dependência \\
\hline Gaussiana & $\left(\Phi^{-1}(u), \Phi^{-1}(v) ; \theta\right)$ & $\theta \in[-1,1]$ \\
FGM & $u v+\theta u v(1-u)(1-v)$ & $\theta \in[-1,1]$ \\
AMH & $\frac{u v}{1-\theta(1-u)(1-v)}$ & $\theta \in[-1,1]$ \\
Frank & $\theta^{-1} \log \left[1+\left(e^{-\theta u}-1\right)\left(e^{-\theta v}-1\right) /\left(e^{-\theta}-1\right)\right]$ & $\theta \in \mathbb{R} \backslash\{0\}$ \\
Clayton & $\left(u^{-\theta}+v^{-\theta}-1\right)^{-\frac{1}{\theta}}$ & $\theta \in(0, \infty)$ \\
Joe & $1-\left[(1-u)^{\theta}+(1-v)^{\theta}-(1-u)^{\theta}(1-v)^{\theta}\right]^{\frac{1}{\theta}}$ & $\theta \in(1, \infty)$ \\
Gumbel & $\exp \left\{-\left[(-\log u)^{\theta}-(-\log v)^{\theta}\right]^{\frac{1}{\theta}}\right\}$ & $\theta \in(0, \infty)$
\end{tabular}

Fonte : Radice, Marra e Wojtys (2013) e Nelsen (2016).

Notas: $\Phi_{2}$ é função de densidade acumulada normal bivariada padrão com coeficiente de correlação $\theta ; \Phi^{-1}$ é a inversa da função acumulada normal padrão; $u$ e $v$ são distribuições marginais. 
Tabela A3 - Testes de RV e Wald para combinação de escolhas

\begin{tabular}{lcc}
\hline Ho: Alternativas podem ser combinadas & Teste RV (Qui-Quadrado) & Teste de Wald (F) \\
\hline Migrar e trabalhar em outro município & $935,15^{\star \star \star}[0,000]$ & $20,93^{\star \star \star}[0,000]$ \\
Migrar e não trabalhar em outro município & $2.580,20^{\star \star *}[0,000]$ & $50,33^{\star \star \star}[0,000]$ \\
Não migrar e trabalhar em outro município & $2.009,8^{\star \star \star}[0,000]$ & $32,16^{\star \star \star}[0,000]$ \\
Não migrar e não trabalhar em outro município & $411,28^{\star \star \star}[0,000]$ & $9,62^{\star \star \star}[0,000]$
\end{tabular}

Fonte: Elaboração própria a partir dos microdados do Censo Demográfico de 2010.

Nota: Hipótese nula: alternativas são indistinguíveis. P-valor entre colchetes. ${ }^{* * *}$ Estatisticamente significativo a $1 \%$.

\section{Tabela A4 - Testes de especificação de Hausman}

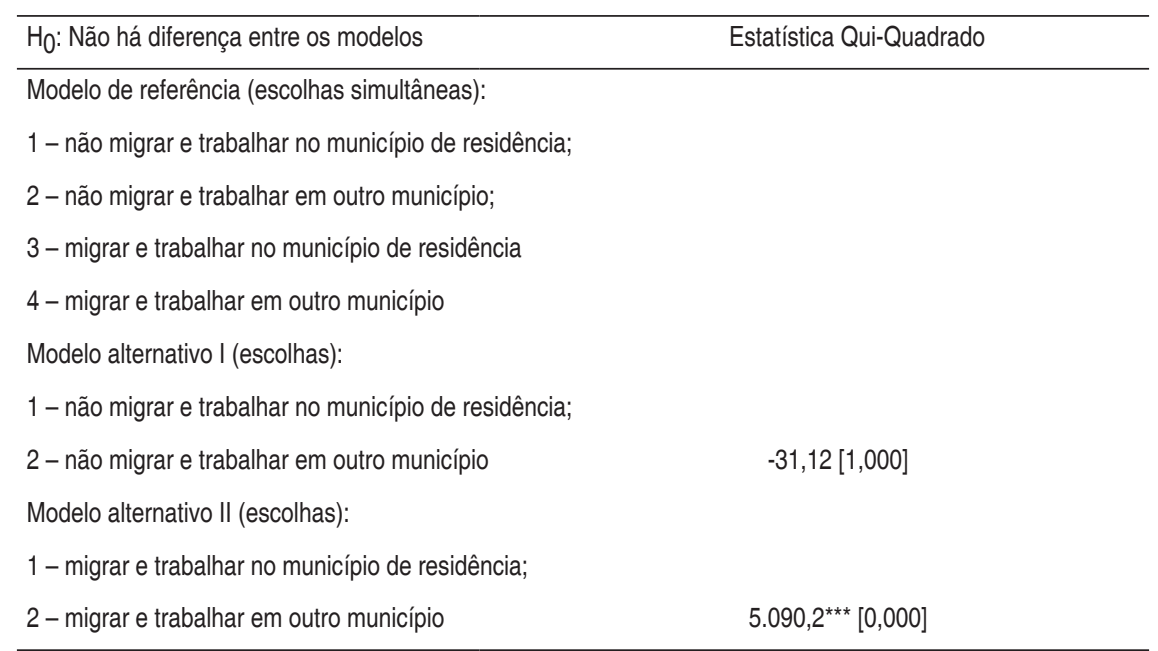

Fonte: Elaboração própria a partir dos microdados do Censo Demográfico de 2010. Nota: P-valor entre colchetes. ${ }^{* * *}$ Estatisticamente significativo a 1\%. 
Tabela A5 - Critério de informação BIC: seleção de modelos segundo a função cópula e diferentes especificações

\begin{tabular}{|c|c|c|c|c|c|c|c|}
\hline & (1) & & (2) & & (3) & & (4) \\
\hline Cópula & $\mathrm{BIC}$ & Cópula & $\mathrm{BIC}$ & Cópula & $\mathrm{BIC}$ & Cópula & $\mathrm{BIC}$ \\
\hline Joe 90 & 38786,79 & Gumbel 270 & 33326,20 & Frank & 33029,17 & Frank & 33025,33 \\
\hline Gumbel 90 & 38787,85 & Gaussiana & 33326,75 & Gumbel 270 & 33030,39 & Gumbel 270 & 33027,90 \\
\hline Clayton 270 & 38789,26 & FGM & 33331,40 & Gaussiana & 33031,14 & Gaussiana & 33031,71 \\
\hline AMH & 38792,05 & Clayton 270 & 33331,47 & FGM & 33032,00 & Clayton 90 & 33032,05 \\
\hline Joe 180 & 38792,09 & Clayton 90 & 33333,20 & Clayton 90 & 33035,19 & FGM & 33032,94 \\
\hline Gumbel 180 & 38792,09 & Joe 270 & 33333,81 & Joe 270 & 33036,03 & Joe 270 & 33032,95 \\
\hline Gaussiana & 38792,60 & Gumbel 90 & 33334,22 & $\mathrm{AMH}$ & 33036,56 & $\mathrm{AMH}$ & 33041,02 \\
\hline Clayton & 38792,67 & Joe 90 & 33336,62 & Clayton 270 & 33037,94 & Clayton 270 & 33045,77 \\
\hline Frank & 38792,74 & $\mathrm{AMH}$ & 33336,96 & Gumbel 90 & 33039,87 & Gumbel 90 & 33049,13 \\
\hline FGM & 38792,88 & Joe & 33339,16 & Joe 90 & 33040,31 & Joe 90 & 33051,87 \\
\hline Clayton 90 & 38792,97 & Clayton 180 & 33339,46 & Joe & 33040,51 & Clayton & 33054,18 \\
\hline Clayton 180 & 38792,97 & Clayton & 33340,48 & Clayton 180 & 33040,66 & Clayton 180 & 33054,18 \\
\hline Joe & 38792,97 & Joe 180 & 33340,48 & Clayton & 33040,72 & Joe & 33054,18 \\
\hline Joe 270 & 38792,97 & Gumbel & 33340,48 & Joe 180 & 33040,72 & Joe 180 & 33054,18 \\
\hline Gumbel & 38792,97 & Gumbel 180 & 33340,48 & Gumbel & 33040,72 & Gumbel & 33054,18 \\
\hline Gumbel 270 & 38792,97 & Frank & 33340,91 & Gumbel 180 & 33040,72 & Gumbel 180 & 33054,18 \\
\hline \multicolumn{8}{|l|}{ Especificação } \\
\hline Variáveis pessoais & $\operatorname{sim}$ & & $\operatorname{sim}$ & & $\operatorname{sim}$ & & $\operatorname{sim}$ \\
\hline Dummies municipais & não & & $\operatorname{sim}$ & & $\operatorname{sim}$ & & $\operatorname{sim}$ \\
\hline Variáveis locacionais & não & & não & & sim & & $\operatorname{sim}$ \\
\hline Restrição de exclusão & não & & não & & não & & $\operatorname{sim}$ \\
\hline
\end{tabular}

Fonte: Elaboração própria a partir dos microdados do Censo Demográfico de 2010.

Nota: Variáveis pessoais: gênero, cor da pele, faixas de instrução, posição no domicílio, convivência com cônjuge, número de filhos por faixa etária, presença de idosos aposentados; variáveis locacionais por estrato de setores domiciliares: valor médio de aluguel, distância até a capital (Recife), Quocientes locacionais (agricultura, indústria, serviços, social e administração pública), Área do setor, infraestrutura (proporção de domicílios com acesso à água encanada, proporção de domicílios com acesso à coleta de lixo, proporção de domicílios com acesso à internet); dummies municipais: variáveis binárias por município de residência; restrição de exclusão: proporção de migrantes com 6 a 9 anos de residência no estrato de setores. 
Quadro A.1 - Descrição das variáveis selecionadas para a análise empírica

\begin{tabular}{|c|c|c|c|}
\hline Variável & Tipo & Códigos & Descrição \\
\hline Masculino & Binária & V0601 & $\begin{array}{l}1 \text { - se o indivíduo é do sexo mas- } \\
\text { culino; } 0 \text { caso contrário. }\end{array}$ \\
\hline $\begin{array}{l}\text { Feminino (categoria omi- } \\
\text { tida) }\end{array}$ & Binária & V0601 & $\begin{array}{l}1 \text { - se o indivíduo é do sexo femi- } \\
\text { nino; } 0 \text { caso contrário. }\end{array}$ \\
\hline Branca (categoria omitida) & Binária & V0606 & $\begin{array}{l}1 \text { - se o indivíduo declarou-se de } \\
\text { cor branca; } 0 \text { caso contrário. }\end{array}$ \\
\hline Preta & Binária & V0606 & $\begin{array}{l}1 \text { - se o indivíduo declarou-se de } \\
\text { cor preta; } 0 \text { caso contrário. }\end{array}$ \\
\hline Parda & Binária & V0606 & $\begin{array}{l}1 \text { - se o indivíduo declarou-se de } \\
\text { cor parda; } 0 \text { caso contrário }\end{array}$ \\
\hline Amarela/Vermelha & Binária & V0606 & $\begin{array}{l}1 \text { - se o indivíduo declarou-se de } \\
\text { cor amarela ou vermelha; } 0 \text { caso } \\
\text { contrário. }\end{array}$ \\
\hline Idade & Contínua & V6036 & Idade do entrevistado em anos. \\
\hline Idade ao quadrado & Contínua & V6036 & $\begin{array}{l}\text { Quadrado da diferença entre a } \\
\text { idade do indivíduo e a média de } \\
\text { idade de todos indivíduos na } \\
\text { amostra. }\end{array}$ \\
\hline $\begin{array}{l}\text { S/ instrução e fund. Incomple- } \\
\text { to (categoria omitida) }\end{array}$ & Binária & V6400 & $\begin{array}{l}1 \text { - se o indivíduo não tem ins- } \\
\text { trução ou tem curso fundamental } \\
\text { incompleto; } 0 \text { caso contrário. }\end{array}$ \\
\hline $\begin{array}{l}\text { Fund. completo e médio } \\
\text { incompleto }\end{array}$ & Binária & V6400 & $\begin{array}{l}\text { 1- se o indivíduo tem curso funda- } \\
\text { mental completo ou nível médio } \\
\text { incompleto; } 0 \text { caso contrário. }\end{array}$ \\
\hline $\begin{array}{l}\text { Médio completo e superior } \\
\text { incompleto }\end{array}$ & Binária & V6400 & $\begin{array}{l}1 \text { - se o indivíduo tem nível mé- } \\
\text { dio completo ou curso superior } \\
\text { incompleto; } 0 \text { caso contrário. }\end{array}$ \\
\hline Superior completo & Binária & V6400 & $\begin{array}{l}1 \text { - se } 0 \text { indivíduo tem curso su- } \\
\text { perior completo; } 0 \text { caso contrário. }\end{array}$ \\
\hline Não chefe (categoria omitida) & Binária & V0502 & $\begin{array}{l}\text { 1- se o indivíduo não é a pessoa } \\
\text { responsável pelo domicílio; } 0 \text { caso } \\
\text { contrário. }\end{array}$ \\
\hline Chefe (categoria omitida) & Binária & V0502 & $\begin{array}{l}1 \text { - se o indivíduo é a pessoa } \\
\text { responsável pelo domicílio; } 0 \text { caso } \\
\text { contrário. }\end{array}$ \\
\hline $\begin{array}{l}\text { Não há cônjuge (categoria } \\
\text { omitida) }\end{array}$ & Binária & V0637 & $\begin{array}{l}1 \text { - se o indivíduo não vive com } \\
\text { cônjuge; } 0 \text { caso contrário }\end{array}$ \\
\hline Vive com cônjuge & Binária & V0637, V0502, V0619 & $\begin{array}{l}\text { 1- se } 0 \text { indivíduo vive com } \\
\text { cônjuge; } 0 \text { caso contrário. }\end{array}$ \\
\hline N. de crianças ( 0 a 5 anos) & Contínua & V0502, V6036, V0300 & $\begin{array}{l}\text { Número de filhos do chefe do } \\
\text { domicílio com idade entre } 0 \text { e } 5 \\
\text { anos. }\end{array}$ \\
\hline N. de crianças (6 a 9 anos) & Contínua & V0502, V6036, V0300 & $\begin{array}{l}\text { Número de filhos do chefe do } \\
\text { domicílio com idade entre } 6 \text { e } 9 \\
\text { anos. }\end{array}$ \\
\hline N. de crianças (10 a 14 anos) & Contínua & V0502, V6036, V0300 & $\begin{array}{l}\text { Número de filhos do chefe do do- } \\
\text { micílio com idade entre } 10 \text { e } 14 \\
\text { anos. }\end{array}$ \\
\hline
\end{tabular}


Quadro A.1 - Descrição das variáveis selecionadas para a análise empírica (Continuação)

\begin{tabular}{|c|c|c|c|}
\hline Variável & Tipo & Códigos & Descrição \\
\hline $\begin{array}{l}\text { N. aposentados/pensionistas } \\
\text { (>65 anos) }\end{array}$ & Contínua & V6036, V0656, V0300 & $\begin{array}{l}\text { Número de pessoas mais de } 65 \\
\text { anos de idade aposentadas e/ou } \\
\text { pensionistas morando no domi- } \\
\text { cílio. }\end{array}$ \\
\hline Migrante & Binária & V0002, V6264, V0618 & $\begin{array}{l}1 \text { - se o indivíduo é migrante in- } \\
\text { termunicipal de data fixa dentro } \\
\text { da RMR; } 0 \text { caso nasceu e sempre } \\
\text { morou no município de residência. }\end{array}$ \\
\hline $\begin{array}{l}\text { Prop. domicílios com rede } \\
\text { de água }\end{array}$ & Contínua & $\begin{array}{l}\text { V0300, V0010, V0011, } \\
\text { V1004, V0208 }\end{array}$ & $\begin{array}{l}\text { Proporção de domicílios com rede } \\
\text { de água na APC de residência do } \\
\text { indivíduo. }\end{array}$ \\
\hline Prop. domicílios com internet & Contínua & $\begin{array}{l}\text { V0300, V0010, V0011, } \\
\text { V1004, V0202 }\end{array}$ & $\begin{array}{l}\text { Proporção de domicílios com } \\
\text { microcomputador com acesso à } \\
\text { internet na APC de residência do } \\
\text { indivíduo. }\end{array}$ \\
\hline Distância até Recife (km) & Contínua & $\begin{array}{l}\text { V0011, Malhas digitais do } \\
\text { IBGE e Google }\end{array}$ & $\begin{array}{l}\text { Distância rodoviária da APC de } \\
\text { residência do indivíduo até o } \\
\text { marco zero da capital Recife. }\end{array}$ \\
\hline Valor de aluguel - $\mathrm{R} \$$ (em log) & Contínua & $\begin{array}{l}\text { V0300, V0010, V0011, } \\
\text { V1004, V2011 }\end{array}$ & $\begin{array}{l}\text { Valor médio do aluguel domiciliar } \\
\text { na APC de residên cia do indiví- } \\
\text { duo. }\end{array}$ \\
\hline Área do estrato - km2 (em log) & Contínua & $\begin{array}{l}\text { V0300, V0010, V0011, } \\
\text { V1004 e malhas digitais } \\
\text { do IBGE. }\end{array}$ & $\begin{array}{l}\text { Área da APC de residência do } \\
\text { indivíduo. }\end{array}$ \\
\hline $\begin{array}{l}\text { Prop. domicílios com coleta } \\
\text { de lixo }\end{array}$ & Contínua & $\begin{array}{l}\text { V0300, V0010, V0011, } \\
\text { V1004, V0210 }\end{array}$ & $\begin{array}{l}\text { Proporção de domicílios com co- } \\
\text { leta de lixo na APC de residência } \\
\text { do indivíduo. }\end{array}$ \\
\hline $\begin{array}{l}\text { Quociente locacional - } \\
\text { Agricultura }\end{array}$ & Contínua & $\begin{array}{l}\text { V0300, V0010, V0011, } \\
\text { V1004, V6471, V0660 }\end{array}$ & $\begin{array}{l}\text { Quociente locacional para o setor } \\
\text { de Agricultura na APC de residên- } \\
\text { cia do indivíduo. }\end{array}$ \\
\hline $\begin{array}{l}\text { Quociente locacional - } \\
\text { Indústria }\end{array}$ & Contínua & $\begin{array}{l}\text { V0300, V0010, V0011, } \\
\text { V1004, V6471, V0660 }\end{array}$ & $\begin{array}{l}\text { Quociente locacional para o setor } \\
\text { de Indústria na APC de residência } \\
\text { do indivíduo. }\end{array}$ \\
\hline $\begin{array}{l}\text { Quociente locacional - } \\
\text { Serviços }\end{array}$ & Contínua & $\begin{array}{l}\text { V0300, V0010, V0011, } \\
\text { V1004, V6471, V0660 }\end{array}$ & $\begin{array}{l}\text { Quociente locacional para o setor } \\
\text { de Serviços na APC de residência } \\
\text { do indivíduo. }\end{array}$ \\
\hline Quociente locacional - Social & Contínua & $\begin{array}{l}\text { V0300, V0010, V0011, } \\
\text { V1004, V6471, V0660 }\end{array}$ & $\begin{array}{l}\text { Quociente locacional para o setor } \\
\text { Social na APC de residência do } \\
\text { indivíduo. }\end{array}$ \\
\hline $\begin{array}{l}\text { Quociente locacional - } \\
\text { Adm. Pública }\end{array}$ & Contínua & $\begin{array}{l}\text { V0300, V0010, V0011, } \\
\text { V1004, V6471, V0660 }\end{array}$ & $\begin{array}{l}\text { Quociente locacional para } 0 \\
\text { setor de Adm. Pública na APC de } \\
\text { residência do indivíduo. }\end{array}$ \\
\hline Prop. de imigrantes recentes & Contínua & $\begin{array}{l}\text { V0300, V0010, V0011, } \\
\text { V1004, V0618, V0624 }\end{array}$ & $\begin{array}{l}\text { Razão entre o total de imigrantes } \\
\text { não naturais do município com } 6 \text { a } \\
9 \text { anos de residência por e a popu- } \\
\text { lação residente por APC. }\end{array}$ \\
\hline Abreu e Lima & Binária & V0002 & $\begin{array}{l}1 \text { - se o indivíduo reside em Abreu } \\
\text { e Lima; } 0 \text { caso contrário. }\end{array}$ \\
\hline
\end{tabular}




\section{Quadro A.1 - Descrição das variáveis selecionadas para a análise empírica} (Continuação)

\begin{tabular}{|c|c|c|c|}
\hline Variável & Tipo & Códigos & Descrição \\
\hline Araçoiaba & Binária & V0002 & $\begin{array}{l}1 \text { - se o indivíduo reside em } \\
\text { Araçoiaba; } 0 \text { caso contrário. }\end{array}$ \\
\hline Cabo de Santo Agostinho & Binária & V0002 & $\begin{array}{l}1 \text { - se o indivíduo reside em Cabo } \\
\text { de Santo Agostinho; } 0 \text { caso con- } \\
\text { trário. }\end{array}$ \\
\hline Camaragibe & Binária & V0002 & $\begin{array}{l}1 \text { - se o indivíduo reside em } \\
\text { Camaragibe; } 0 \text { caso contrário. }\end{array}$ \\
\hline Igarassu & Binária & V0002 & \begin{tabular}{|l|}
1 - se o indivíduo reside em \\
Igarassu; 0 caso contrário. \\
\end{tabular} \\
\hline Ipojuca & Binária & V0002 & $\begin{array}{l}1 \text { - se o indivíduo reside em } \\
\text { Ipojuca; } 0 \text { caso contrário. }\end{array}$ \\
\hline Ilha de Itamaracá & Binária & V0002 & $\begin{array}{l}1 \text { - se o indivíduo reside em llha } \\
\text { de Itamaracá; } 0 \text { caso contrário. }\end{array}$ \\
\hline Itapissuma & Binária & V0002 & $\begin{array}{l}1 \text { - se o indivíduo reside em Itapis- } \\
\text { suma; } 0 \text { caso contrário }\end{array}$ \\
\hline Jaboatão dos Guararapes & Binária & V0002 & $\begin{array}{l}1 \text { - se o indivíduo reside em } \\
\text { Jaboatão dos Guararapes; } 0 \text { caso } \\
\text { contrário. }\end{array}$ \\
\hline Moreno & Binária & V0002 & $\begin{array}{l}1 \text { - se } 0 \text { indivíduo reside em } \\
\text { Moreno; } 0 \text { caso contrário. }\end{array}$ \\
\hline Olinda & Binária & V0002 & $\begin{array}{l}1 \text { - se o indivíduo reside em } \\
\text { Olinda; } 0 \text { caso contrário. }\end{array}$ \\
\hline Paulista & Binária & V0002 & $\begin{array}{l}1 \text { - se o indivíduo reside em } \\
\text { Paulista; } 0 \text { caso contrário. }\end{array}$ \\
\hline São Lourenço da Mata & Binária & V0002 & $\begin{array}{l}1 \text { - se o indivíduo reside em } \\
\text { São Lourenço da Mata; } 0 \text { caso } \\
\text { contrário. }\end{array}$ \\
\hline Recife (categoria omitida) & Binária & V0002 & $\begin{array}{l}\text { 1- se o indivíduo reside em Recife; } \\
0 \text { caso contrário. }\end{array}$ \\
\hline
\end{tabular}

Fonte: Elaboração própria. 


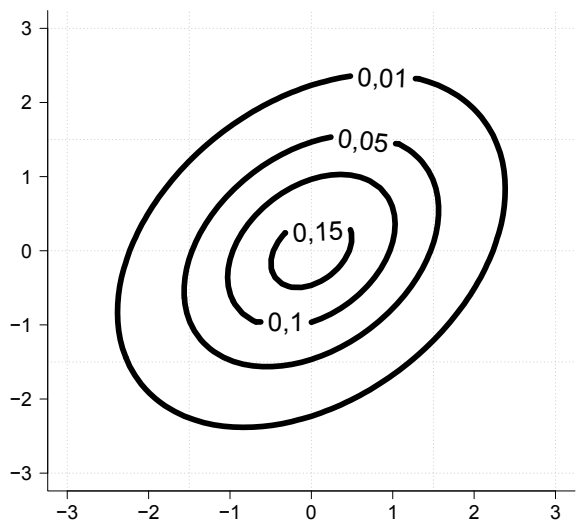

Figura A.1. a - Guassiana

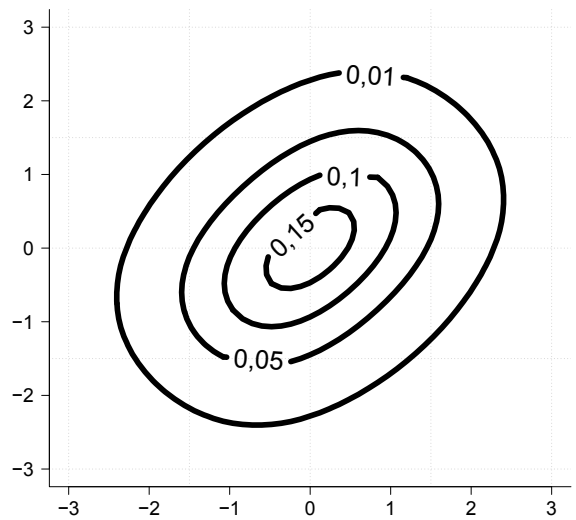

Figura A.1. b - Frank

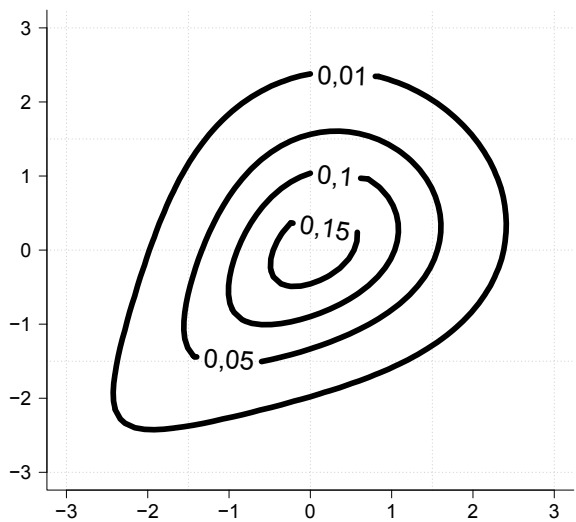

Figura A.1. c - Clayton 


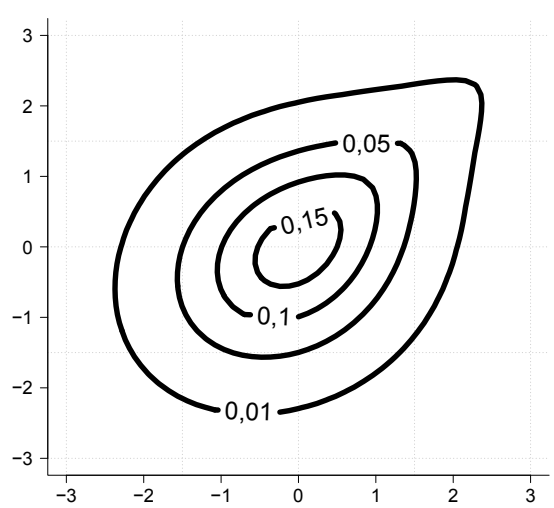

Figura A.1. d - Gumbel

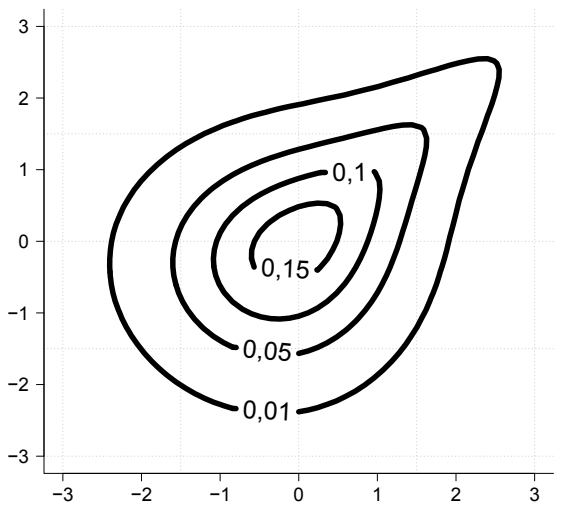

Figura A.1. e - Joe

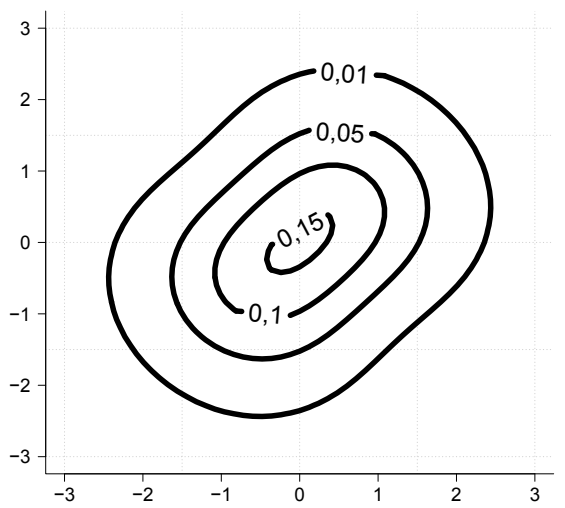

Figura A.1. f -FGM 


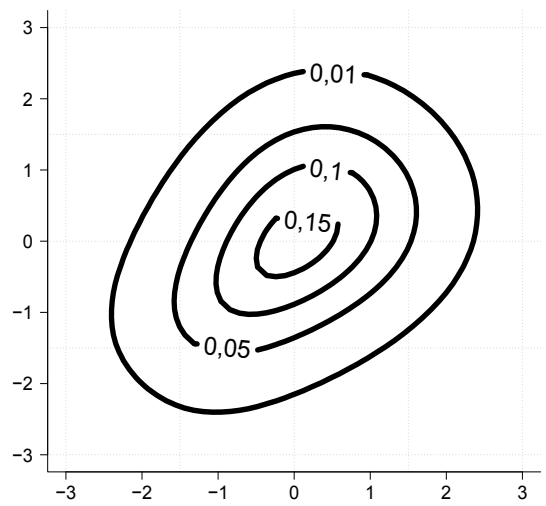

Figura A.1. g - AMH

Figura A.1 - Curvas de nível de diferentes funções cópulas

Fonte: Elaboração própria.

Nota: Dados simulados considerando variáveis aleatórias com distribuição marginal normal padrão e de Kendall igual a 0,22.

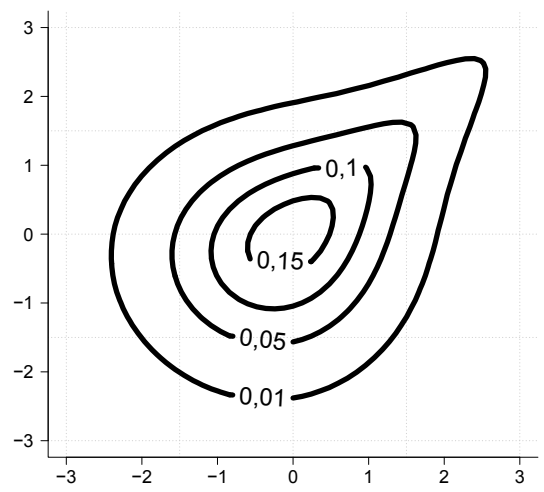

Figura A.2. a - Rotação $0^{0}$ 


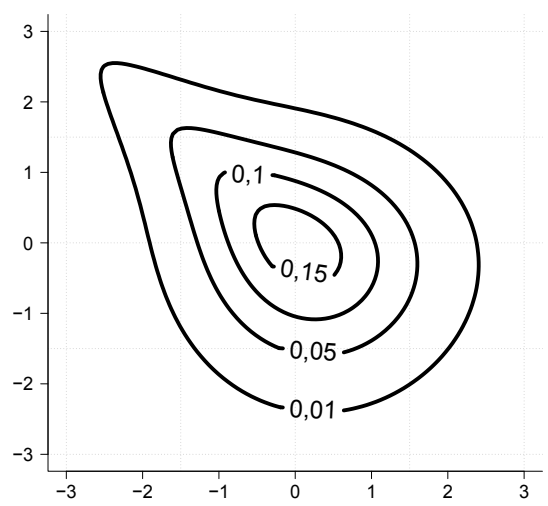

Figura A.2. b - Rotação $90^{0}$

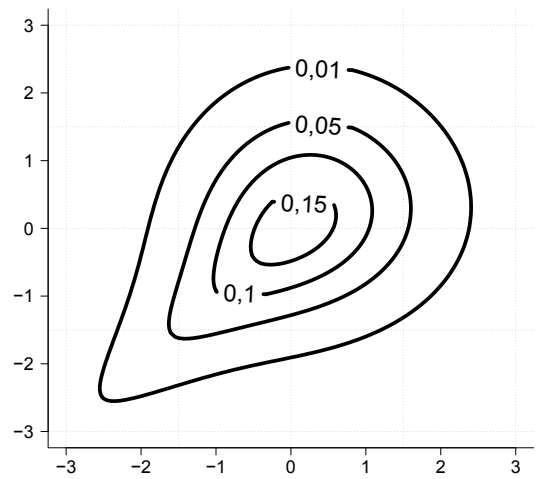

Figura A.2. c - Rotação $180^{0}$

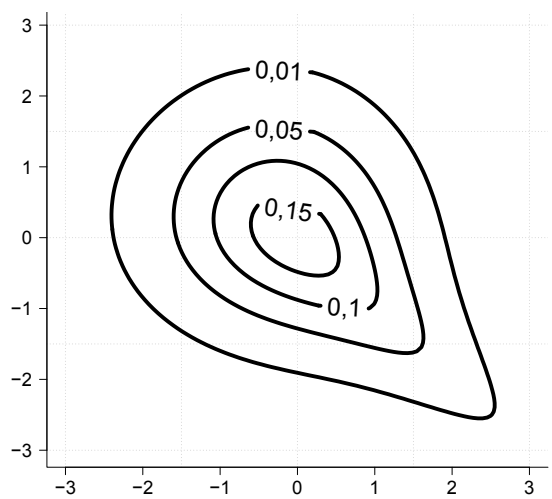

Figura A.2. D - Rotação $270^{0}$

Figura A.2 - Curvas de nível de funções cópulas Joe com diferentes rotações Fonte: Elaboração própria.

Nota: Dados simulados considerando variáveis aleatórias com distribuição marginal normal padrão e $\tau$ de Kendall igual a 0,22 para dependência positiva e -0,22 para dependência negativa. 